\title{
Morphology and Defect Control of Metal Halide Perovskite Films for High-Performance Optoelectronics
}

\author{
Lei Lei ${ }^{\dagger \dagger}$, Ming Li ${ }^{\dagger *}$, David M. Grant ${ }^{\dagger}$, Songwang Yang ${ }^{\ddagger}, \mathrm{Yu} \mathrm{Yu}^{\dagger}$, Julie A. Watts ${ }^{\S}$ and David B. \\ Amabilino ${ }^{\text {II } *}$ \\ ${ }^{\dagger}$ Advanced Materials Research Group, Faculty of Engineering, University of Nottingham, University Park, Nottingham NG7 \\ 2RD, United Kingdom \\ $\$$ CAS Key Laboratory of Materials for Energy Conversion, Shanghai Institute of Ceramics, Chinese Academy of Sciences, \\ Shanghai 201899, China \\ ${ }^{\S}$ School of Pharmacy, University of Nottingham, University Park, Nottingham NG7 2RD, United Kingdom \\ "I School of Chemistry and The GSK Carbon Neutral Laboratories for Sustainable Chemistry, University of Nottingham, \\ Triumph Road, Nottingham NG7 2TU, United Kingdom
}

\begin{abstract}
Delicate morphology and defect control are crucial for high-performance optoelectronics. For metal halide perovskites, anti-solvent precipitation is the most common process to realise the control and develop the state-of-art devices. However, the solute/solvent/anti-solvent interactions and their influence on the film formation process are unclear. Here, we propose a novel solubility parameter $\delta_{\mathrm{DN}}$ to measure the coordinate interaction between solvent and perovskite precursors. A combination of $\delta_{\mathrm{DN}}$ and Hansen's Solubility Parameters allows the first comprehensive analysis of interactions between pure liquids and the perovskite precursors. The relative energy difference $(R E D)$ between anti-solvent and solvent is used to quantify the supersaturation level during film deposition. Dense morphology films form in the maximum supersaturation region $(0.85<R E D<1.00)$. Perovskite properties are controlled by the interaction behaviour difference in anti-solvent/solutes. The photovoltaic performance increases by $53 \%$ when RED increases from 0.416 to 0.858 . We demonstrate that detailed knowledge of the physicochemical characteristics of the solutions used to form films of perovskites is a valuable tool in the discovery of optimum film formation conditions and consequently in attaining efficient optoelectronic performance.
\end{abstract}

\section{INTRODUCTION}

Halide perovskites are making solar energy more appealing than ever, with recent power conversion efficiency (PCE) surpassing $25 \%$ by solution-processed films ${ }^{1}$. So-called "solvent engineering" ${ }^{2-15}$ is vital to prepare an active layer with favourable morphology and low trap densities. Anti-solvents are used to precipitate the perovskite rapidly during spin coating ${ }^{10,11,16-29}$. The interplay between halide salts, solvent and anti-solvent determine the film formation.

There have been a few attempts to interpret the relationship between solute-solvent interactions and film formation. These efforts include the Mayer bond $\operatorname{order}^{30}$ and $\mathrm{Pb}$-solvent ${ }^{31-33}$ coordination. The coordinate bond strength between the solute (acceptor) and the solvent (donor) depends on their Lewis acidity and basicity. Gutmann ${ }^{34}$ proposed a donor number to quantify the Lewis basicity of a solvent $\left(D N\right.$, in kcal mol ${ }^{-1}$, is the absolute value of formation enthalpy of a 1:1 adduct between the Lewis base and $\mathrm{SbCl}_{5}$ ). Evaluation of the interaction strength between perovskite precursors and solvents based on Gutmann's $D N$ has been proposed ${ }^{35}$. For example, a $D N$ value of $18 \mathrm{kcal} \mathrm{mol}^{-1}$ was identified as a threshold to be able to form a stable precursor solution. However, many liquids with high $D N$ values are not solvents for perovskite precursors.
Pyridine $\left(D N=33.1 \mathrm{kcal} \mathrm{mol}^{-1}\right)$ and triethylamine $(D N=61$ $\mathrm{kcal}^{\mathrm{mol}}{ }^{-1}$ ) for instance are poor solvents. This discrepancy indicates there are still other interactions which determine the solubility of perovskite precursors in liquids.

Besides coordination, interactions in the forms of dispersion forces, polarity relevant forces and hydrogen bonding exist between solute and solvent ${ }^{36}$. These interactions could be quantified by Hansen's Solubility Parameters (HSPs) ${ }^{37,38}$ which are square roots of energy densities (cohesion energy divided by molar volume):

$$
\delta_{i}=\sqrt{\frac{E_{i}}{V}}
$$

Where $E_{i}$ and $\delta_{i}$ are $i$ part (D (dispersion), $\mathrm{P}$ (polarity) and $\mathrm{H}$ (hydrogen bonding)) of cohesion energies and corresponding solubility parameters, and $V$ is the molar volume. Researchers have applied HSPs in choosing non-hazardous solvents based on their positions in $\delta_{\mathrm{D}}-\delta_{\mathrm{P}}$ and $\delta_{\mathrm{D}}-\delta_{\mathrm{H}}$ plots $^{39}$. However, the locations highly overlap in $\delta_{\mathrm{D}}-\delta_{\mathrm{P}}$ and $\delta_{\mathrm{D}}-\delta_{\mathrm{H}}$ plots for some pure liquids that perovskite precursors have different solubilities in. Neglecting coordinate interaction makes the prediction on solubilities of perovskite precursors solely based on HSPs less 
effective. Due to insufficient understanding on the processproperty relationship, the a n t i -

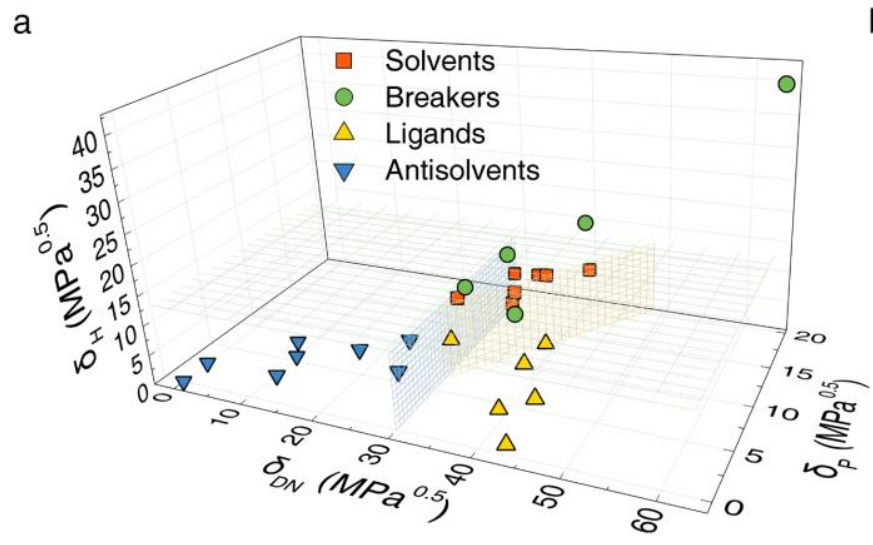

C

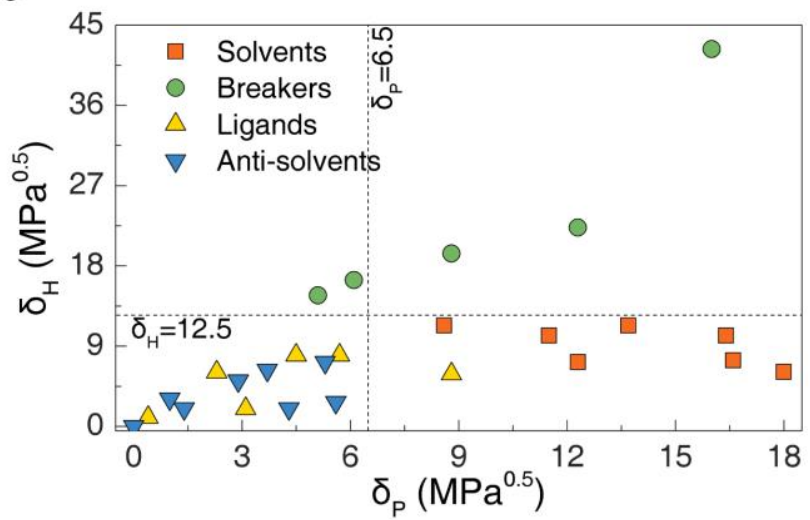

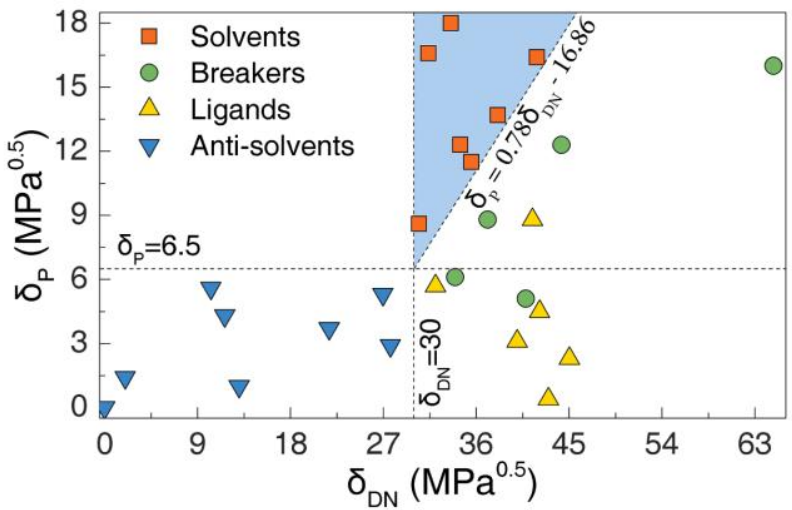

d

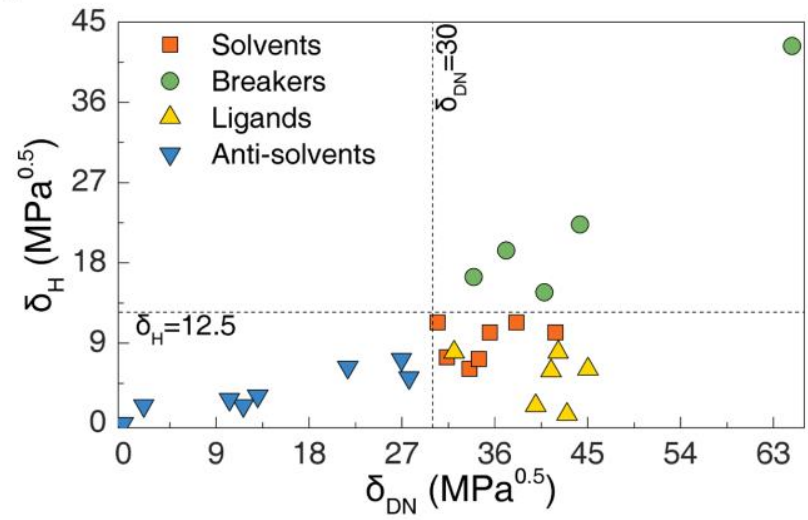

Figure 1. (a) Distribution of a variety of pure liquids in the $\delta_{\mathrm{DN}}-\delta_{\mathrm{P}}-\delta_{\mathrm{H}}$ space. The grids are blue: $\delta_{\mathrm{DN}}=30 \mathrm{MPa}{ }^{0.5}$, yellow: $\delta_{\mathrm{P}}=0.78 \delta_{\mathrm{DN}}-$ $16.86 \mathrm{MPa}^{0.5}$, green: $\delta_{\mathrm{H}}=12.5 \mathrm{MPa}^{0.5}$. The projections of $\delta_{\mathrm{DN}}-\delta_{\mathrm{P}}-\delta_{\mathrm{H}}$ are plotted in (b) $\delta_{\mathrm{DN}}-\delta_{\mathrm{P}},(\mathrm{c}) \delta_{\mathrm{DN}}-\delta_{\mathrm{P}}$ and $(\mathrm{d}) \delta_{\mathrm{P}}-\delta_{\mathrm{H}}$ planes. Table $\mathrm{S} 1$ lists the detailed $\delta_{\mathrm{DN}}$, Hansen Solubility Parameters $\left(\mathrm{HSPs}^{40}\right)$ and physical properties of these liquids.

solvents used in perovskite film fabrication tend to be empirically derived.

This work aims at obtaining a comprehensive view on the interactions between perovskite precursors and solvents. Based on an analysis combining coordinate, dispersion, polarity related and hydrogen bonding interactions, this work interprets the interaction-film formation relationship. The film morphology and properties are correlated to the interaction behaviour difference between anti-solvent/solvent and antisolvent/perovskite precursors. This work proposes a method to design perovskite films with desired morphology and defects for a wide range of applications. This work also provides a guidance for selecting greener solvents with lower cost for solution-based film deposition.

\section{RESULTS AND DISCUSSION}

Interaction between halide salts and pure liquids. The solubility of a solid in a liquid depends on their interaction strength. Due to bonding polarity difference, $\mathrm{PbI}_{2}$ and $\mathrm{CH}_{3} \mathrm{NH}_{3} \mathrm{I}$ (methylammonium iodide, MAI) have different solubilities in pure liquids. With high bonding polarity, MAI dissolves in most polar solvents under strong dipole related electrostatic forces. Conversely, the highly covalent $\mathrm{PbI}_{2}$ has very low solubilities in many polar solvents. Strong donor-acceptor coordination is required to dissolve $\mathrm{PbI}_{2}$. This work introduces a new solubility parameter $\delta_{\mathrm{DN}}$ to quantify the coordinate cohesion between $\mathrm{PbI}_{2}$ and donor solvents:

$$
\delta_{D N}=\sqrt{\frac{D N}{V}}
$$

Where $D N$ and $V$ are the Gutmann's donor number and the molar volume of the solvent, respectively. $\delta_{\mathrm{DN}}$ has the same form as HSPs (square root of energy density) and is believed to be able to extend HSPs to cover coordination interactions. The position of a liquid in $\delta_{\mathrm{DN}}-\delta_{\mathrm{D}}-\delta_{\mathrm{P}}-\delta_{\mathrm{H}}$ space comprehensively describes its interaction behaviour to a solute. However, it is not straightforward to visualise four-dimensional coordinate. Fortunately, the $\delta_{\mathrm{D}}$ of pure liquids are generally similar compared to other parameters. In most cases, $\delta_{\mathrm{DN}}-\delta_{\mathrm{P}}-\delta_{\mathrm{H}}$ space is adequate to describe the interaction behaviour difference of liquids.

This work classifies pure liquids into four categories according to their $\left(\delta_{\mathrm{DN}}, \delta_{\mathrm{P}}, \delta_{\mathrm{H}}\right)$ (interaction behaviour to $\mathrm{PbI}_{2}$ and MAI). Figure 1a plots the $\left(\delta_{\mathrm{DN}}, \delta_{\mathrm{P}}, \delta_{\mathrm{H}}\right)$ of various common liquids (Table S1 also lists the detailed values, the $\delta_{\mathrm{P}}$ and $\delta_{\mathrm{H}}$ of other liquids can be found from Hansen's book ${ }^{40}$ ). Solvents for perovskite precursors locate in the grids surrounded space (blue 
grid: $\delta_{\mathrm{DN}}=30 \mathrm{MPa}^{0.5}$; yellow grid: $\delta_{\mathrm{p}}=0.78 \delta_{\mathrm{DN}}-16.86 \mathrm{MPa}^{0.5}$ and green grid: $\left.\delta_{\mathrm{H}}=12.5 \mathrm{MPa}^{0.5}\right)$. The solvent- $\mathrm{Pb}$ coordination polarises the $\mathrm{Pb}-\mathrm{I}$ bond $^{36,41}$. Correspondingly, the molecular polarity $\left(\delta_{\mathrm{P}}\right)$ of the solvent should match its Lewis basicity $\left(\delta_{\mathrm{DN}}\right)$ to dissolve the coordination compounds. Based on this consideration, a linear boundary was plotted to separate good and poor solvents for $\mathrm{PbI}_{2}\left(\delta_{\mathrm{P}}=0.78 \delta_{\mathrm{DN}}-16.86 \mathrm{MPa}^{0.5}\right.$ in Figure 1b). The difference in hydrogen bonding interaction strength causes solubility mismatch between $\mathrm{PbI}_{2}$ and MAI. A $\delta_{\mathrm{H}}$ of < 12.5 $\mathrm{MPa}^{0.5}$ is required to ensure balanced solubilities for $\mathrm{PbI}_{2}$ and MAI. Donor solvents are generally proton acceptors. The protons in protic liquids compete with $\mathrm{Pb}$ as electron lone pair acceptors. The competition decreases the solubility of $\mathrm{PbI}_{2}$ in protic donor solvents. Besides, protic liquids and MAI have stronger interactions for the strong hydrogen bonding between $-\mathrm{OH}$ and $-\mathrm{NH}_{3}$ in MAI. The solubility of MAI in protic solvents are higher than aprotic solvents with the same $\delta_{\mathrm{P}}$. Enabling strong interactions and high solubilities to both $\mathrm{PbI}_{2}$ and MAI, solvents can dissolve perovskite precursors which allows film deposition, crystal growth and quantum dot synthesis.

Breakers (circles in Figure 1) are liquids that $\mathrm{PbI}_{2}$ and MAI have mismatched solubilities in. In most cases, the mismatch origins from low $\mathrm{PbI}_{2}$ solubility. As discussed above, liquids with (i) insufficient Lewis basicity $\left(\delta_{\mathrm{DN}}<30 \mathrm{MPa}^{0.5}\right)$, (ii) insufficient polarity $\left(\delta_{\mathrm{DN}}>30 \mathrm{MPa}^{0.5} \& \delta_{\mathrm{P}}<0.78 \delta_{\mathrm{DN}}-16.86\right.$ $\mathrm{MPa}^{0.5}$, e.g. tetrahydrofuran) and (iii) strong protic behaviour $\left(\delta_{\mathrm{H}}>12.5 \mathrm{MPa}^{0.5}\right.$, e.g. water and alcohols) have low $\mathrm{PbI}_{2}$ solubilities. Breakers have strong interaction with MAI $\left(\delta_{\mathrm{P}}>\right.$ $6.5 \mathrm{MPa}^{0.5}$ or $\delta_{\mathrm{H}}>12.5 \mathrm{MPa}^{0.5}$ ) and selectively solubilise MAI. The large interaction behaviour difference of breakers (especially $\mathrm{H}_{2} \mathrm{O}$ ) to alkali and lead halides makes them an important factor threatening the long-term function and storage of perovskite materials and devices.

Liquids with $\delta_{\mathrm{P}}<6.5 \mathrm{MPa}^{0.5}$ and $\delta_{\mathrm{H}}<12.5 \mathrm{MPa}^{0.5}$ have low $\mathrm{PbI}_{2}$ and MAI solubilities for insufficient interaction strength. In terms of Lewis basicity, they are further classified as ligands $\left(\delta_{\mathrm{DN}} \geq 30 \mathrm{MPa}^{0.5}\right.$, up-pointing triangles in Figure 1$)$ and antisolvents $\left(\delta_{\mathrm{DN}}<30 \mathrm{MPa}^{0.5}\right.$, down-pointing triangles in Figure 1$)$. Ligands can form stable coordination compounds with $\mathrm{PbI}_{2}$ and perovskite. To verify the coordination compound formation, triethylamine $\left(\mathrm{TEA}, \delta_{\mathrm{DN}}=42.91 \mathrm{MPa}^{0.5}\right.$, pure and $1 \mathrm{vol} \%$ in chlorobenzene (CB)) was used to quench the wet film during perovskite precursor solution spin coating. Figure S1 shows the powder X-ray diffraction (PXRD) patterns of as-cast films. A strong diffraction peak located at $10^{\circ}$ in $2 \theta$ confirmed the formation of a TEA coordination compound $\mathrm{MAPbI}_{3} \cdot x \mathrm{TEA}$. Formation of coordination compounds allows passivation or modification of the perovskite surface and grain boundaries. Ligand modification is an important method to enhance the charge separation at the perovskite/carrier transporter interface $^{42}$. Hydrophobic ligands with long alkyl chains have been used to improve the moisture stability of perovskite films ${ }^{43}$. Surface modification by ligand molecules is also beneficial for the dispersion and stability of perovskite quantum dots $^{44}$. Anti-solvents can be used to prepare high-quality perovskite films. They are also useful in the fabrication of quantum dots and the purification of precursor salts by recrystallization.
Dependence of intermediate phase structure on $\delta_{\mathrm{DN}}$. The solvation of $\mathrm{Pb}$ requires both high $\delta_{\mathrm{DN}}$ and $\delta_{\mathrm{P}}$. Specifically, a negative charge localised on the donor atoms is required. Hence, aprotic oxygen donor solvents are favourable because of the high affinity of oxygen to Lewis acids. Typical oxygen donor solvents include $\gamma$-butyrolactone (GBL), $N$-methyl-2pyrrolidone (NMP) $\mathrm{N}, \mathrm{N}$-dimethylacetamide (DMAC), $\mathrm{N}, \mathrm{N}$ dimethylformamide (DMF) and dimethyl sulfoxide (DMSO), etc.

Table 1 lists the $\delta_{\mathrm{DN}}$ values of GBL, NMP, DMAC, DMF and DMSO. The coordinate interaction strength between $\mathrm{Pb}$ and these solvents should increase in the above order. Intermediate films formed from different solvents and perovskite precursors were studied to verify this. As the PXRD results in Figure $2 \mathrm{a}$ shown, films formed by DMF and DMSO have three peaks in $5-10^{\circ}$ range while the other samples have only one near $8^{\circ}$ in 20. According to previous studies ${ }^{45}$, DMF and DMSO form $(\mathrm{MAI})_{2}(\mathrm{Sol})_{2} \mathrm{~Pb}_{3} \mathrm{I}_{8}$ (space group: Pnnm, Sol = solvent) and $(\mathrm{MAI})_{2}(\mathrm{Sol})_{2} \mathrm{~Pb}_{2} \mathrm{I}_{6}$ (space group: $P 2_{l} / c$ ) intermediates with needle-shaped morphology, while GBL forms a polyhedronshaped $(\mathrm{MA})_{8}(\mathrm{GBL})_{\mathrm{x}} \mathrm{Pb}_{18} \mathrm{I}_{44}$ intermediate ${ }^{46}$. There are no reports on the crystal structure of DMAC and NMP based intermediates. However, the PXRD pattern similarity implies they share the same crystal structure with GBL. The SEM images of as-cast films were in accordance with the PXRD results (Figure 2f). Intermediates formed from GBL/NMP/DMAC and perovskite precursors were polyhedrons while the others were needle-like. The crystal structures of intermediates differ in the manner of intercalation of solvent molecules in the $\mathrm{PbI}_{6}$ networks (Figure 2c, 2d). With higher $\delta_{\mathrm{DN}}$ values, the $\mathrm{Pb}-\mathrm{O}$ bonds in DMF and DMSO solutions have higher dissociation energies. During the formation of $\mathrm{PbI}_{6}$ octahedra, the released molecules were captured by $\mathrm{MA}^{+}$(by forming hydrogen bonds). These molecules hence inserted in the spaces between face sharing $\mathrm{PbI}_{6}$ planes (Figure 2d, 2e). On the contrary, with lower donor abilities $\left(\delta_{\mathrm{DN}}<38.09 \mathrm{MPa}^{0.5}\right)$, GBL, NMP and DMAC molecules were released faster and could not be effectively captured by $\mathrm{MA}^{+}$. The $\mathrm{PbI}_{6}$ octahedra hence quickly packed into edge shared $3 \mathrm{D}$ networks in these solvents.

Table 1. The $\delta_{\mathrm{DN}}$, vapour pressure $(P)$, intermediate phase composition and spontaneous nucleation time $\left(t_{S N}\right)$ of solvents for perovskite formation.

\begin{tabular}{|c|c|c|c|c|c|}
\hline Solvents & GBL & NMP & DMAC & DMF & DMSO \\
\hline$\delta_{\mathrm{DN}}\left(\mathrm{MPa}^{0.5}\right)$ & 31.37 & 34.47 & 35.53 & 38.09 & 41.90 \\
\hline$P(\mathrm{~Pa})$ & 200.0 & 31.6 & 300.0 & 516.0 & 55.6 \\
\hline Intermediates & \multicolumn{3}{|c|}{$(\mathrm{MA})_{8}(\mathrm{Sol})_{\mathrm{X}} \mathrm{Pb}_{18} \mathrm{I}_{44}$} & \multicolumn{2}{|c|}{$\begin{array}{l}(\mathrm{MAI})_{2}(\mathrm{Sol})_{2} \mathrm{~Pb}_{3} \mathrm{I}_{8} \\
(\mathrm{MAI})_{2}(\mathrm{Sol})_{2} \mathrm{~Pb}_{2} \mathrm{I}_{6}\end{array}$} \\
\hline$t_{S N}(\mathrm{~s})^{*}$ & 15 & 36 & 12 & 6 & 30 \\
\hline
\end{tabular}

* Measured under a temperature of $20^{\circ} \mathrm{C}$.

During the spin coating of precursor solutions, the clear wet films clouded up, indicating the spontaneous nucleation of the solutes. This work defines the time span between rotation start and opacification observed as the spontaneous nucleation time $\left(t_{S N}\right)$. The $t_{S N}$ of a solution depends on the evaporation rate $(E)$ of the solvent, which is a function of how tightly the molecules 
are bound to themselves and the solute. The higher the $E$ is, the smaller the $t_{S N}$ is. The solvent molecules in the perovskite precursor solutions have cohesion forces with themselves and the solutes ( $\mathrm{Pb}-\mathrm{O}$ coordinate bonding). The vapour pressure $(P)$

a

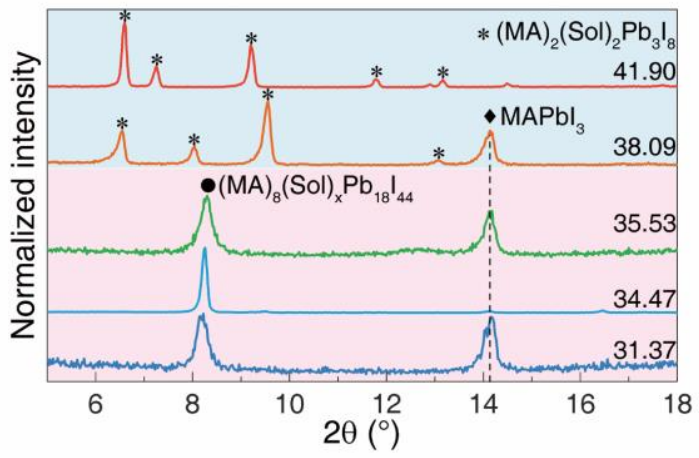

C

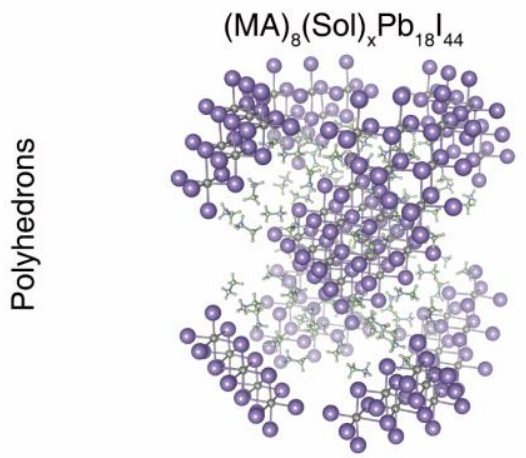

of the solvent quantifies the former, while $\delta_{\mathrm{DN}}$ is a scale of the latter. Solvents with larger $P$ evaporate quicker and have smaller $t_{S N}$ (negative relevance of $t_{S N}$ to

b

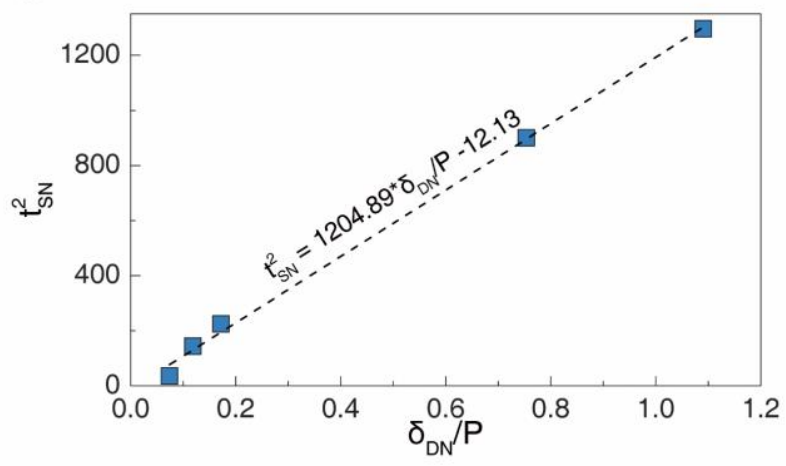

d

e

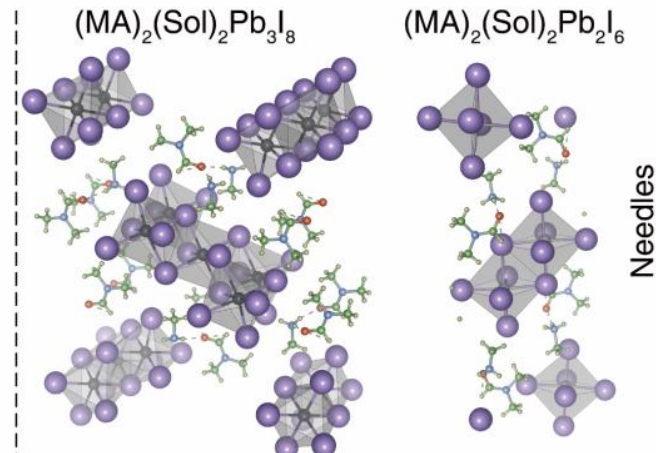

$f$

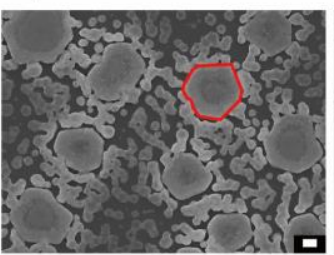

31.37

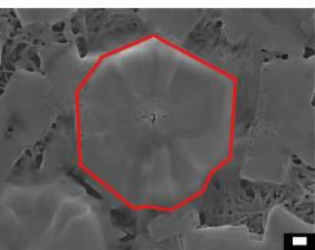

34.47

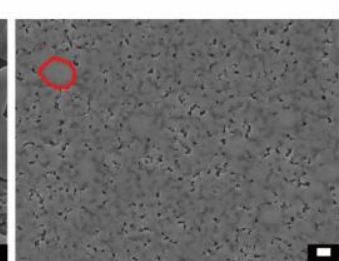

35.53

$\delta_{\mathrm{DN}}\left(\mathrm{MPa}^{0.5}\right)$

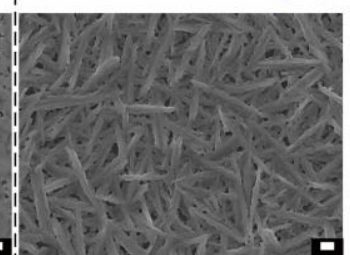

38.09

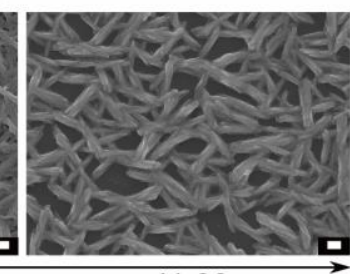

41.90

Figure 2. (a) The powder X-ray diffraction patterns of the as-cast films formed from perovskite precursor solutions in solvents with different $\delta_{\mathrm{DN}}$; (b) The $t_{S N^{2}}-\delta_{\mathrm{DN}} / P$ plot of perovskite precursor solutions $(1.5 \mathrm{M})$ in different solvents. The $t_{S N}$ values of different perovskite precursor solutions are obtained by measuring the time period between rotation start and the wet films opacification during spin coating (4000 rpm at room temperature $\sim 18^{\circ} \mathrm{C}$ ). The linear fitting gives a relationship of $t_{S N}{ }^{2}=(1204.9 \pm 33.3) \delta \mathrm{DN} / P-(12.13 \pm 20.04)$. (c) Illustration of the cluster formed between GBL and $\mathrm{MAPbI}_{3}$; (d) and (e) Illustration of primitive cells of intermediates formed between DMF and $\mathrm{MAPbI}_{3}$; (f) Evolution of as-cast film morphology formed from perovskite precursors in solvents with different $\delta_{\mathrm{DN}}$. The scale bars represent $1 \mu \mathrm{m}$.

$P)$. On the other hand, the solvents with larger $\delta_{\mathrm{DN}}$ are more tightly bound to the solute ( $t_{S N}$ is positively relevant to $\left.\delta_{\mathrm{DN}}\right)$. Logically, there is a positive relation between $t_{S N}$ and $\delta_{\mathrm{DN}} / P$ (Figure 2b). The crystal structure trend of intermediates and the $t_{S N}-\delta_{\mathrm{DN}}$ relation validate the effectiveness of $\delta_{\mathrm{DN}}$ in quantifying the coordination strength between lead halide and donor solvents.

Impact of anti-solvent on precursor solution. There are many species in a perovskite precursor solution. Main compositions in a dilute solution are ions and solvent coordinated iodoplumbates (solvates) ${ }^{31,47}$. The existence of iodoplumbates has been proved by well-defined light absorption peaks ${ }^{48,49}$. The precursor solutions used for solar cell fabrication generally have concentrations over $1 \mathrm{M}$ where colloids exist $^{50,51}$. Figure 3 a proposes equilibria between ions, iodoplumbates and intermediate clusters. The existence of colloids was verified by cryo-TEM imaging (Figure 3b-3d). The frozen DMF underwent morphology change during electron beam exposure (Figure S2). DMF is amorphous after quenching to $-180{ }^{\circ} \mathrm{C}$ and starts to crystallise at $-125^{\circ} \mathrm{C}^{52}$. The incident electrons presumably heat the sample and cause crystallisation of frozen DMF during imaging. The crystallised DMF has flake structures (Figure $3 b$ ). No electron beam induced morphology change was observed for the frozen perovskite precursor solution. Containing ions and iodoplumbates, the frozen precursor solution had smaller grains 
than the DMF flakes. The dark structures in the bright field images (Figure 3c, 3d) are ascribed to solid colloids.

Considering $\delta_{\mathrm{DN}}$ is much larger than HSPs, the coordination compounds (iodoplumbates) formed from solvent molecules and perovskite precursors can be regarded as a whole. This

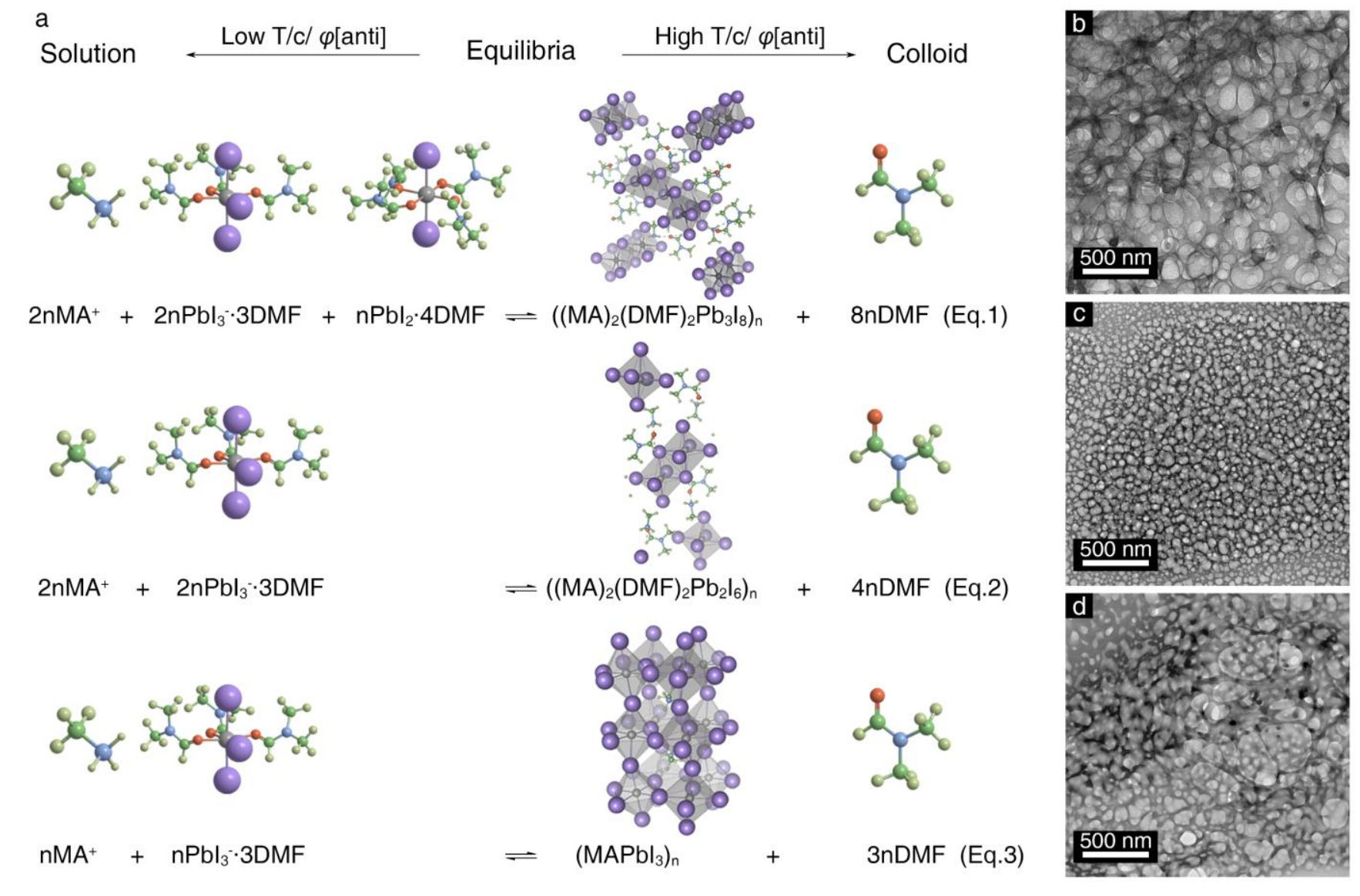

work treated iodoplumbates as new solutes with dispersion, polarity related and hydrogen bonding (between coordinated solvent molecules and free solvent molecules) interactions with the solvent molecules. Introducing an anti-solvent into a p e r o v s k i t e precursor s o l u t i o n

Figure 3. (a) Illustration of species that compose a perovskite precursor solution. Equilibria exist between molecular-scale particles and submicrometre colloids. The former includes solvent molecules, solvent molecule bound ions and solvate molecule coordinated iodoplumbates. The latter is mainly intermediate clusters. In other words, they are soft networks of $\mathrm{PbI}_{6} \mathrm{surrounded} \mathrm{by} \mathrm{MA}^{+}$and solvent molecules which have crystal structures of $\left((\mathrm{MAI})_{2}(\mathrm{DMF})_{2} \mathrm{~Pb}_{3} \mathrm{I}_{8}:\right.$ Pnnm, $(\mathrm{MAI})_{2}(\mathrm{Sol})_{2} \mathrm{~Pb}_{2} \mathrm{I}_{6}: P 2_{1} / c$ and MAPbI 3 : I4/mcm); Cryo-TEM (bright field) images of (b) blank DMF and (c) \& (d) $1.5 \mathrm{M}$ perovskite precursor solution in DMF.

dilutes the solvent molecules that surround the solutes $\left(\mathrm{MA}^{+}\right.$ and iodoplumbantes). Consequently, the $\mathrm{Pb}-\mathrm{I}$ bonds replace $\mathrm{Pb}$ $\mathrm{O}$ bonds for the weak interactions between anti-solvent and solutes. The concentration of iodoplumbantes with larger iodine numbers $\left(\mathrm{PbI}_{3}, \mathrm{PbI}_{4}\right)$ would hence increase. When the solvent molecule density around the solute is small enough, colloids would form.

Figure $4 \mathrm{a}$ illustrates the static mixing experiment to check the anti-solvent precipitation depth. CB $(1 \mathrm{~mL})$ was carefully injected to the precursor solution $(1.5 \mathrm{M}, 200 \mu \mathrm{L}$ in DMF) without disturbance. Consequently, a dense precipitate layer formed for the counter diffusion between $\mathrm{CB}$ and the precursor solution. The observed intermediate layer was about $2 \mathrm{~mm}$ thick. During spin coating, the expected wet-film thickness is tens of microns. Hence, the anti-solvent will precipitate the entire wet film if the anti-solvent/wet film interface exists long enough. After shaking, a homogeneous suspension formed indicating the rightward move of the equilibria in Figure 3 when an anti-solvent introduced.

The concentration of iodoplumbates in precursor solutions of $\mathrm{DMF} / \mathrm{CB}$ mixtures with respect to the $\mathrm{CB}$ volume fraction $\left(\varphi_{C B}\right)$ was investigated. Figure $\mathrm{S} 3$ shows the absorbance spectra of precursor solutions $(625 \mu \mathrm{M})$ in $\mathrm{CB} / \mathrm{DMF}$ mixtures. The iodoplumbates have several sets of peaks in the ultra-violet (UV) and visible regions. These absorbance bands correspond to the electron transition of sp orbitals or the ligand to metal charge transfer (LMCT) process. Since the LMCT peaks locate at 205 and $223 \mathrm{~nm}^{48}$, the electron transition in the $\mathrm{Pb}$ sp orbitals causes the absorbance peaks observed in Figure S3. Table 2 summarises the absorbance peak positions and light extinction coefficients $(\varepsilon)$ of $\mathrm{PbI}_{2}, \mathrm{PbI}_{3}$ and $\mathrm{PbI}_{4}$.

Table 2. The absorption peaks of iodoplumbates and corresponding molar extinction coefficients $(\varepsilon)$. 


\begin{tabular}{c|c|c|c|c|c}
\hline Solvates & $\mathrm{PbI}_{2}$ & \multicolumn{2}{|c|}{$\mathrm{PbI}_{3}$} & \multicolumn{2}{c}{$\mathrm{PbI}_{4}$} \\
\hline Peaks $(\mathrm{nm})$ & 290 & 321 & 366 & 408 & 425 \\
\hline $\begin{array}{c}\varepsilon\left(\mathrm{L} \mathrm{mol}^{-1} \mathrm{~cm}^{-}\right. \\
{ }^{-}\end{array}$ & $10000^{53}$ & $6730^{48}$ & $7040^{48}$ & $11500^{49}$ & - \\
\hline
\end{tabular}

a

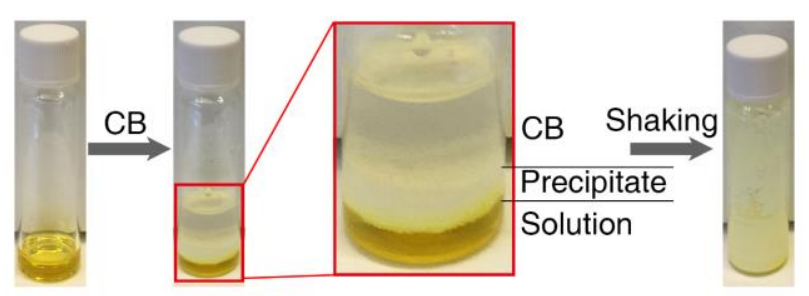

C<smiles>C=CC1CC1</smiles>

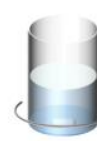

Precipitation liquid

e

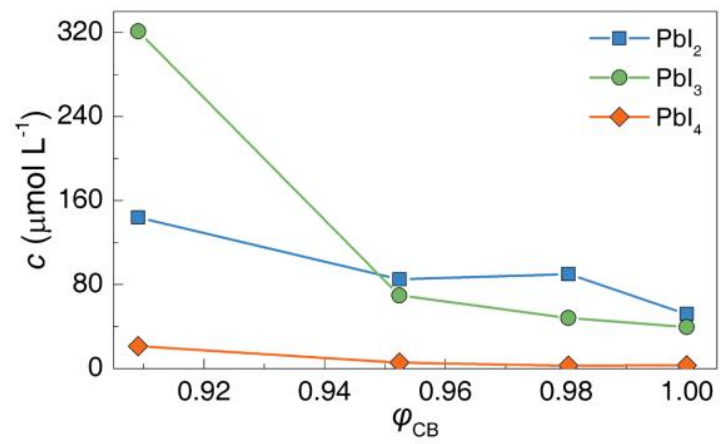

No $\mathrm{PbI}_{4}$ was observed in the $625 \mu \mathrm{M}$ perovskite precursor solution in DMF (Figure 4b). The introduction of CB increased the concentrations of $\mathrm{PbI}_{2}$ and $\mathrm{PbI}_{3}\left(c\left(\mathrm{PbI}_{2}\right)\right.$ and $\left.c\left(\mathrm{PbI}_{3}\right)\right) . c\left(\mathrm{PbI}_{4}\right)$ increased noticeably when $\varphi_{C B}>0.833$. At this stage, the coordinate bonding in highly solvated species (PbI. $x \mathrm{DMF}$ ) starts to dissociate. $\mathrm{PbI}_{3}$ is hence the main product which has a

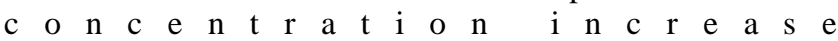

b

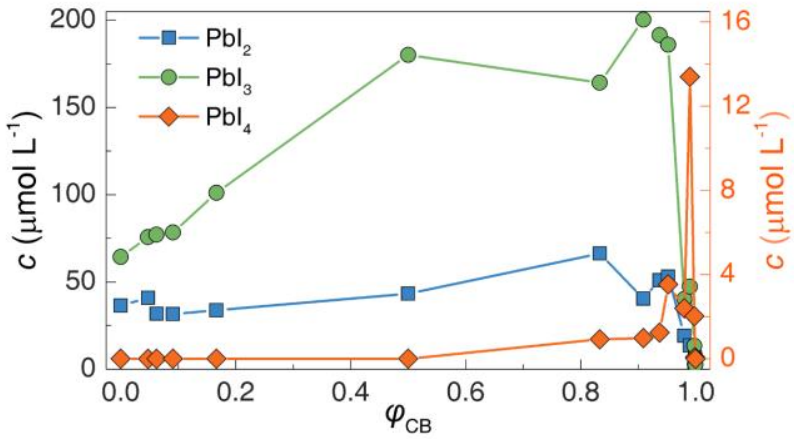

d

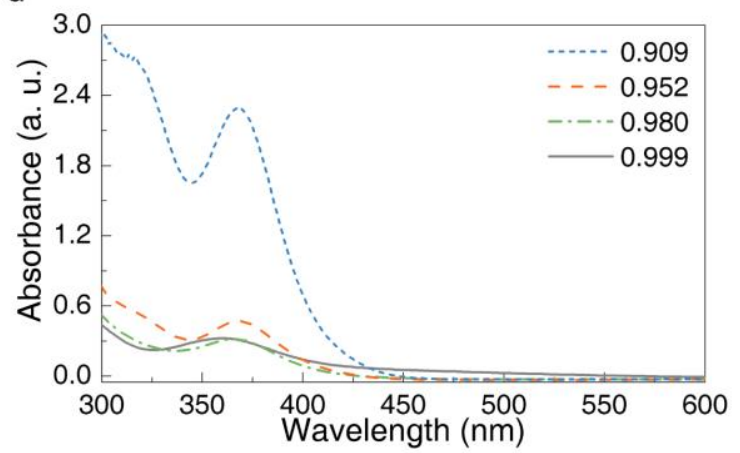

f

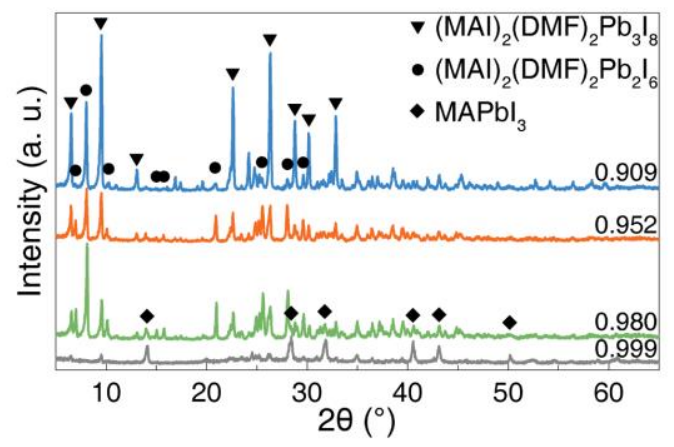

Figure 4. (a) Illustration of static mixing between chlorobenzene (CB) and perovskite precursor solution; (b) evolution of solvate concentrations versus $\mathrm{CB}$ volume fraction $\left(\varphi_{C B}\right)$ obtained by fitting the absorbance spectra of perovskite solutions in $\mathrm{CB} / \mathrm{DMF}$ mixtures. The spectra and fitting results are available in supporting materials; (c) Illustration of the dynamic mixing between perovskite precursor solution and CB/DMF mixtures and the characterisation on derived liquids and solids; (d) The UV-Vis absorbance spectra of the CB/DMF mixtures with $\varphi_{C B}$ from 0.909 to 0.999 after perovskite precipitation; (e) The concentration trend of solvates in (d); (f) The PXRD patterns of the precipitates obtained by adding perovskite solution into CB/DMF mixtures with $\varphi_{C B}$ from 0.909 to 0.999 .

(see Figure $4 \mathrm{~b})$. A high $c\left(\mathrm{PbI}_{4}\right)$ of over $1.24 \mu \mathrm{M}$ was observed for $\varphi_{C B}>0.938$, while $c\left(\mathrm{PbI}_{2}\right)$ and $c\left(\mathrm{PbI}_{3}\right)$ decreased dramatically. These data indicate a transition from $\mathrm{PbI}_{2}$ and $\mathrm{PbI}_{3}$ to $\mathrm{PbI}_{4}$ in this stage. $c\left(\mathrm{PbI}_{4}\right)\left(\right.$ maximum $13.4 \mu \mathrm{M}$ at $\left.\varphi_{C B}=0.990\right)$ is much lower than $c\left(\mathrm{PbI}_{2}\right)$ (maximum $200.3 \mu \mathrm{M}$ at $\varphi_{C B}=0.909$ ) and $c\left(\mathrm{PbI}_{3}\right)$ (maximum $66.3 \mu \mathrm{M}$ at $\varphi_{C B}=0.833$ ). The significantly lower maximal $c\left(\mathrm{PbI}_{4}\right)$ implies a much lower solubility of $\mathrm{PbI}_{4}$. As a result, the formation of colloids competes with $\mathrm{PbI}_{4}$. All solvates have low concentrations with $\varphi_{C B}$ close to 1 , and most of the solutes were precipitated. The scattering effect of the particles caused high background levels in the absorbance spectra (Figure S3). The sharp increase of $c\left(\mathrm{PbI}_{4}\right)$ indicates the saturation of perovskite in the DMF/antisolvent mixture. The sensitivity of $c\left(\mathrm{PbI}_{4}\right)$ to $\varphi$ (anti-solvent) allows measurement of the supersaturation level caused by antisolvents. 
The phase composition of precipitates and the concentrations of iodoplumbates in equilibria were further checked (Figure 4c). Perovskite precursor solutions $(200 \mu \mathrm{L}, 1.5 \mathrm{M})$ were added into $\mathrm{CB} / \mathrm{DMF}$ mixtures $(1.8 \mathrm{~mL})$ with different $\varphi_{C B}$ under stirring. The mixtures were kept stirring for 5 min to reach equilibria. The as-formed suspensions were centrifuged to separate the precipitates from the liquids. Figure $4 \mathrm{~d}$ and $4 \mathrm{f}$ show the absorbance spectra of the liquids and the PXRD patterns of the solids, respectively.

a

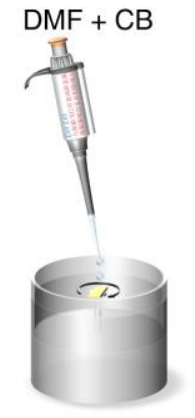

d
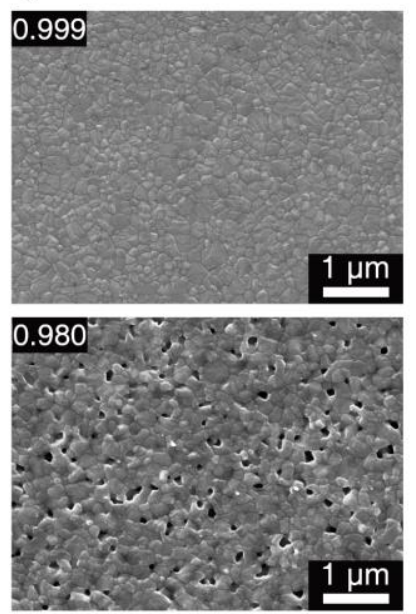

b

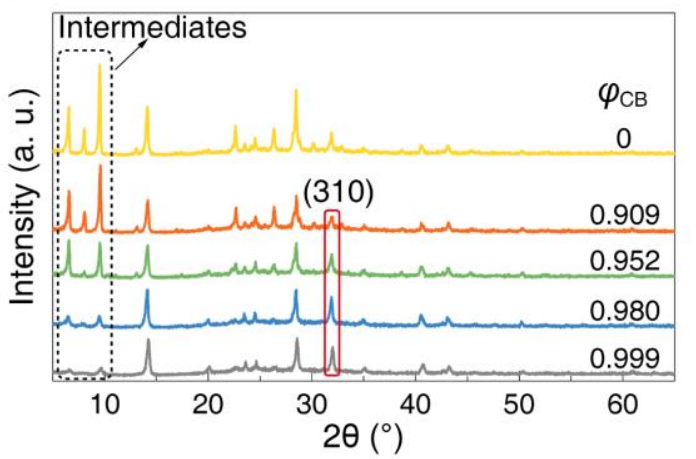

The concentration of iodoplumbates in the mixed liquids decreased with the increase of $\varphi_{C B}$ (Figure 4e). The main composition of precipitate was $(\mathrm{MAI})_{2}(\mathrm{DMF})_{2} \mathrm{~Pb}_{3} \mathrm{I}_{8}$ under a $\varphi_{C B}$ of 0.909 . The main reaction was identified as the rightward moving of equilibrium (1) in Figure $3 \mathrm{a}$. When $\varphi_{C B}$ increased to $\begin{array}{llllllllllll}0 & 9 & 5 & 2 & \mathrm{t} & \mathrm{h} & \mathrm{e}\end{array}$
C

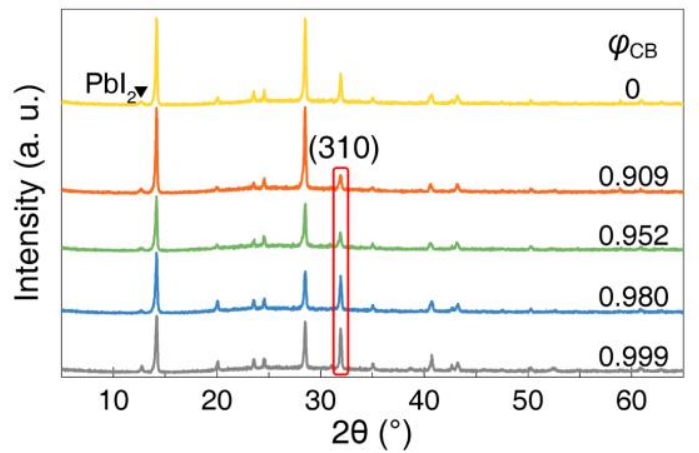

Figure 5. Phase composition and morphology characterisation of perovskite films fabricated by CB/DMF quenching liquids with different CB volume ratios (0.909 - 0.999) and without quenching. (a) an illustration of the film deposition process; PXRD patterns of (b) as-cast and (c) calcined perovskite films and (d) SEM morphologies of calcined perovskite films.

$(\mathrm{MAI})_{2}(\mathrm{DMF})_{2} \mathrm{~Pb}_{2} \mathrm{I}_{6}$ content increased while $c\left(\mathrm{PbI}_{3}\right)$ decreased dramatically. The fast consumption of $\mathrm{PbI}_{3}$ caused the increase of $(\mathrm{MAI})_{2}(\mathrm{DMF})_{2} \mathrm{~Pb}_{2} \mathrm{I}_{6}$ content in the intermediates. At $\varphi_{C B}=$ 0.980 , $(\mathrm{MAI})_{2}(\mathrm{DMF})_{2} \mathrm{~Pb}_{2} \mathrm{I}_{6}$ was the main component in the precipitate. Accordingly, $c\left(\mathrm{PbI}_{3}\right)$ further decreased, while $c\left(\mathrm{PbI}_{2}\right)$ slightly increased. Perovskite became the main composition of precipitate when $\varphi_{C B}$ is close to 1 , and the concentrations of solvates were low. The supersaturation level difference of $\mathrm{MA}^{+}$and iodoplumbates with respect to $\varphi_{C B}$ caused the change in phase composition of precipitate and solvate concentrations in liquids.

The anti-solvent induced supersaturation level increases with $\varphi_{C B}$. The influence of anti-solvents on the film formation process were studied by controlling $\varphi_{C B}$ during anti-solvent precipitation. The PXRD results in Figure 5b show a decrease in the peak intensities of the intermediates with the increase of $\varphi_{C B}$. Compared to the precipitates obtained (with the same $\varphi_{C B}$ ) in the dynamic mixing experiment, higher perovskite contents were observed in the as cast films. The faster evaporation of liquids during spin coating caused the higher perovskite content. Also, with a larger exposure area to the air, the decomposition rates of intermediates in a film are faster than in powders. The perovskite grains formed by the decomposition of intermediates were highly oriented. The (310) peak of the perovskite intensifies with the increase of $\varphi_{C B}$ (Figure 5b). The intensity trends in the (310) diffraction peaks were the same for the as cast and calcined films (Figure 5b, 5c), indicating the perovskite kept the orientation preference after calcination. With the increase of supersaturation level $\left(\varphi_{C B}\right)$, perovskite films changed from needle shape to densely packed polyhedrons (Figure 5d). The low primary nuclei density resulted in a poor coverage of perovskite to the substrate under low $\varphi_{C B}$ (Figure S4). The needles were composed of smaller 
inter-connected polyhedron perovskite grains as shown by the high magnification image (Figure S6).

The above results draw a clear picture on the relationship between anti-solvent volume fraction $\left(\varphi_{\text {anti }}\right)$ and film formation process. At low $\varphi_{a n t}$, the supersaturation level of the solute is low, a low density of intermediate nuclei form. The crystal growth and secondary nucleation processes have comparable rates with primary nucleation (Figure S4). With the increase of $\varphi_{\text {anti }}$, the primary nucleation has higher rate in contrast with the other processes. As a result, the intermediate grains have a

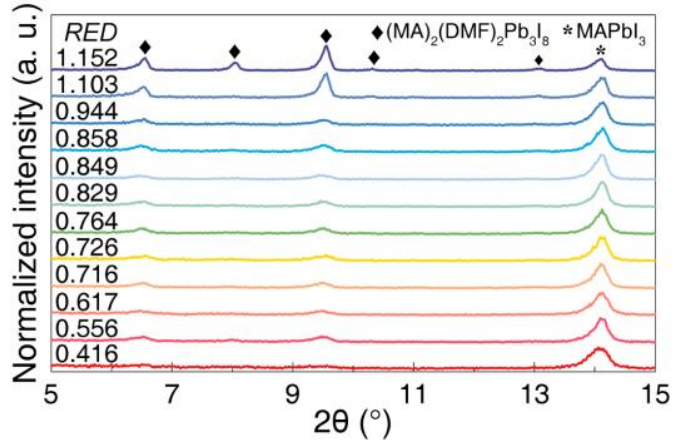

C

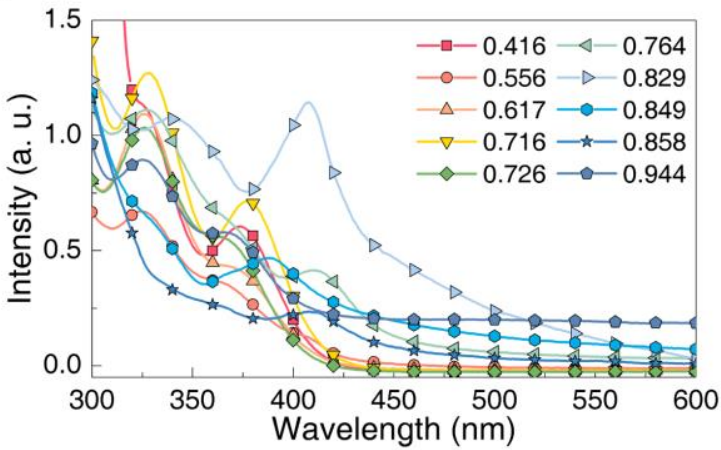

smaller size and denser packing. The main nuclei composition becomes $(\mathrm{MAI})_{2}(\mathrm{DMF})_{2} \mathrm{~Pb}_{2} \mathrm{I}_{6}$ when $\varphi_{\text {anti }}$ further increases to 0.980. $(\mathrm{MAI})_{2}(\mathrm{DMF})_{2} \mathrm{~Pb}_{2} \mathrm{I}_{6}$ crystallites are needle-shape as well. Under higher supersaturation level, the small needles pack into a porous film. (MAI $)_{2}(\mathrm{DMF})_{2} \mathrm{~Pb}_{2} \mathrm{I}_{6}$ decomposes into perovskite easily due to its instability. Hence, compared to the precipitate in the dynamic mixing, the PXRD pattern of as-cast film has lower peak intensities of $(\mathrm{MAI})_{2}(\mathrm{DMF})_{2} \mathrm{~Pb}_{2} \mathrm{I}_{6}$. When pure $\mathrm{CB}$ is the precipitate liquid, the main phase formed in the as-cast film

b

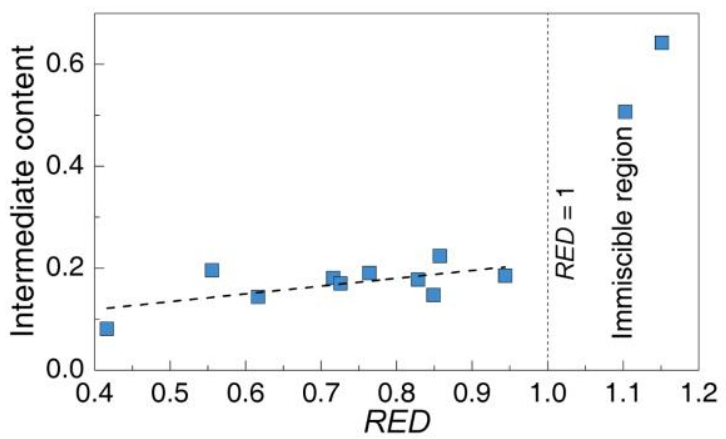

d

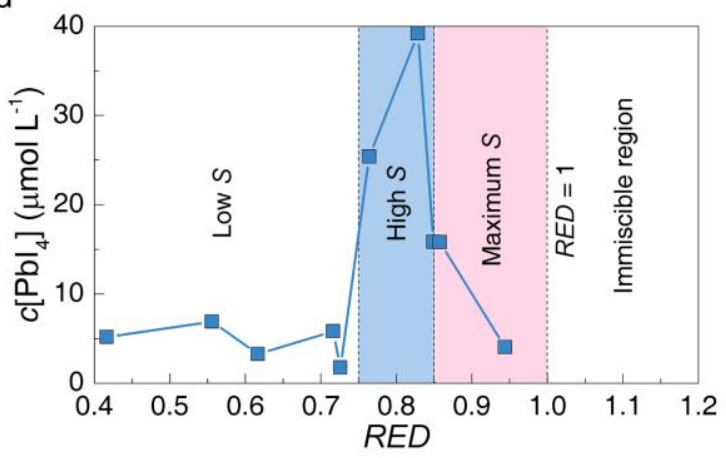

Figure 6. (a) PXRD patterns of as-cast perovskite films prepared with different anti-solvents/DMF REDs; (b) The intermediate content trend in as-cast perovskite films versus anti-solvent/DMF REDs calculated from (a); (c) Absorbance spectra of perovskite solutions in antisolvent/DMF mixture with a fixed anti-solvent volume fraction of 0.952; (d) The $\mathrm{PbI}_{4}$ solvate concentration interpreted from (c).

becomes perovskite. The nuclei density during film formation is high for the maximised supersaturation level. Consequently, the calcined film is compact for the close packing of nuclei.

Control of film morphology. Anti-solvents with different solubility parameters have different interaction strengths with perovskite precursor solutions $\left(\mathrm{MA}^{+}\right.$, iodoplumbates solutes and the solvent). The affinity difference between antisolvent/solvent and anti-solvent/solutes determines the antisolvent quenching induced supersaturation level.

The control of film formation behaviour is possible by using different anti-solvents. During anti-solvent quenching, two factors determine the supersaturation level: the solubility of solutes $(S)$ in the anti-solvent/solvent mixture and the actual $\varphi_{\text {anti }}$ in the quenching process. The system has maximal supersaturation level when the anti-solvent-solvent and antisolvent-solutes affinities are high and low, respectively. However, the solvent and solutes have similar solubility parameters. When anti-solvent/solvent and anti-solvent/solutes have both low affinities, the system has limited $\varphi_{\text {anti. }}$. Conversely, the anti-solvents with strong interactions to both solutes and solvent have large $S$. The systems with high $\varphi_{\text {anti }}$ and low $S$ have maximal supersaturation level. The Relative Energy Difference $(R E D)$ between the solvent and anti-solvent was used to describe the $\varphi_{\text {anti }}$ and $S$ of an anti-solvent quenched system in this work. The following equation defines $R E D$ :

$R E D=\sqrt{\left(\frac{4\left(\delta_{D 2}-\delta_{D 1}\right)^{2}+\left(\delta_{P 2}-\delta_{P 1}\right)^{2}+\left(\delta_{H 2}-\delta_{H 1}\right)^{2}}{R_{0}^{2}}\right)}$

Where $\delta_{\mathrm{D}}, \delta_{\mathrm{P}}$ and $\delta_{\mathrm{H}}$ are the dispersion, polarity and hydrogen bonding HSPs of solvent 1 and anti-solvent $2 . R_{0}$ is the interaction sphere radius of the solvent in $\delta_{\mathrm{D}}-\delta_{\mathrm{P}}-\delta_{\mathrm{H}}$ space. $R_{0}^{2}$ is used to normalise the "distance" of the solubility parameters. For example, the coordinates of DMF and CB are $(17.4,13.7,11.3)$ and $(19.0,4.3,2.0)$ in $\left(\delta_{\mathrm{D}}, \delta_{\mathrm{P}}, \delta_{\mathrm{H}}\right)$ space. Their distance in $\delta_{\mathrm{D}}-\delta_{\mathrm{P}}-\delta_{\mathrm{H}}$ space is $R a=\left(4 *(17.4-19.0)^{2}+(13.7-\right.$ $\left.4.3)^{2}+(11.3-2.0)^{2}\right)^{0.5}=13.60 \mathrm{MPa}^{0.5}$. The molar volume $V$ of DMF is $77.0 \mathrm{~mL} \mathrm{~mol}^{-1}$, which means an interaction radius of $R_{0}$ $=(8 \mathrm{RT} / \mathrm{V})^{0.5}=16.02 \mathrm{MPa}^{0.5}$. The $R E D$ of $\mathrm{CB}$ in DMF is hence $R a / R o=0.849$. 
$R E D$ is a quantitative scale of interaction strength between anti-solvent and solvent. Miscible liquids with strong interaction strength have small RED $(R E D<1)$. Without strong enough molecular interaction when $R E D>1$, the liquids are immiscible. The REDs of the anti-solvent/solute and solvent/solute are not considered here.

The low supersaturation level in a high-RED system comes from the finite miscibility between the solvent and anti-solvent (low actual $\left.\varphi_{\text {anti }}\right)$. Conversely, the high $S$ in a low-RED system limits the supersaturation level. There is a suitable $R E D$ region where the system has simultaneously good miscibility and low $S$.

To identify the $R E D$ region with optimal supersaturation level, a variety of anti-solvents were used in perovskite film fabrication. Table S2 lists the physical properties of these antisolvents and their REDs with DMF. The maximal $\varphi_{\text {anti }}$ of antisolvent/solvent systems were calculated based on the Gibbs free energy $(G)$ (see SI). The anti-solvents are miscible with the solvent at any ratio (infinite solubility, $0 \leq \varphi_{\text {anti }} \leq 1$ ) when $R E D$ $<0.588$ (Figure S10). Anti- solvents with larger REDs have limited solubilities in the solvent. A saturation boundary identified by $G=0$ separates the single-phase and two-phase area. In this work, the volume of anti-solvent is large which yields a high $\varphi_{\text {anti }}$ of over 0.9 . This means that the antisolvent/DMF mixtures are in the single-phase area (if $R E D<$ $1)$.

The as-cast films quenched by different anti-solvents were composed of intermediate and perovskite as shown by PXRD in Figure 6a. The intermediate contents were calculated by fitting the peak areas. When $R E D<1$, the intermediate content increased modestly from 0.1 to 0.2 with the rising $R E D$. The anti-solvent/ solvent affinity decrease resulted in the intermediate content change. A steep intermediate content rise to over 0.5 occurred when $R E D>1$ (Figure 6b). The immiscibility between these anti-solvents and the solvent yielded high intermediate contents. The UV-Vis absorbance spectra of perovskite precursors in DMF/anti-solvent mixtures were recorded. $\varphi_{\text {anti }}$ was fixed at 0.952 to ensure complete mixing (when $R E D<1$ ). As Figure $6 \mathrm{c}$ shows, the solutions have very different absorption bands. The absorbance at $405 \mathrm{~nm}$ was used to interpret $c\left(\mathrm{PbI}_{4}\right) . c\left(\mathrm{PbI}_{4}\right)$ was around $5 \mu \mathrm{mol} \mathrm{L}{ }^{-1}$ for $R E D$ $<0.75$. The low $c\left(\mathrm{PbI}_{4}\right)$ in these liquids were a result of high $\mathrm{PbI}_{2}$ and $\mathrm{PbI}_{3}$ solubilities. $c\left(\mathrm{PbI}_{4}\right)$ underwent a sudden increase to $25 \mu \mathrm{mol} \mathrm{L}^{-1}(R E D=0.764)$ near a $R E D$ of 0.75 , indicating $\mathrm{PbI}_{4}$ and colloids formation. Under a high $R E D$ of $0.944, c\left(\mathrm{PbI}_{4}\right)$ dropped back to $5 \mu \mathrm{mol} \mathrm{L} \mathrm{L}^{-1}$ due to the precipitation of solutes. The light-scattering effect of precipitated particles caused high backgrounds in the absorbance spectra $(R E D \geq 0.764)$. The antisolvent induced supersaturation level increases sharply in 0.75 $<R E D<0.85$ (blue shaded area in Figure 6d). Maximum supersaturation locates in $0.85<R E D<1.00$, where the solutes precipitate in the mixed liquids (red shaded area in Figure $6 \mathrm{~d}$ ).

The morphology of perovskite films formed under different $R E D$ s was studied by FEG-SEM (Figure 7). When $R E D \leq$ 0.726 , the films had pinholes. As mentioned previously, this is attributed to low nuclei density, where the primary nucleation, crystal growth and secondary nucleation processes have comparable rates (Figure $\mathrm{S} 4$ ). With the increase of $R E D$, the packing of perovskite grains became denser. The threshold
$R E D$ of compact perovskite film formation is 0.764 . The perovskite films had grain sizes of $100 \pm 36 \sim 124 \pm 35 \mathrm{~nm}$ when the $R E D$ increased from 0.416 to 0.764 (Figure S12, S13). The grain size has a steep increase in $R E D \geq 0.82$ with a maximum of $240 \pm 95 \mathrm{~nm}$ at $R E D=0.858$. The grain size change is attributed to the differences in supersaturation level and intermediate nuclei content. With lower $\varphi_{\text {anti }}$, there were more residual solvent molecules in the wet film. The decomposition of intermediate released more solvent molecules which facilitated mass transfer during crystal growth (Ostwald ripening).

The above analysis assumed an equilibrium state of the system. However, the systems can be far from equilibrium during film formation. This work considered two kinetic factors: the mutual diffusion of anti-solvent/solvent and evaporation of liquids. The diffusion is fast enough to achieve high $\varphi_{\text {anti }}$ close to equilibrium (see SI, kinetic consideration section). The evaporation rate of anti-solvent determines the residual solvent content in the as-cast film. Consequently, the intermediate content deviated from the linear trend in Figure $6 \mathrm{~b}$ (when $R E D<1$ ). Anti-solvents with low boiling points (BP) evaporate faster, resulting in a lower $\varphi_{\text {anti. }}$ Part of the perovskite crystallites would absorb DMF molecules and form intermediate. Hence, as-cast films quenched by vinyl acetate $\left(R E D=0.556, \mathrm{BP}=72.0^{\circ} \mathrm{C}\right)$ and diethyl ether $(R E D=0.858$, $\mathrm{BP}=34.6^{\circ} \mathrm{C}$ ) had larger intermediate contents. Conversely, the intermediate contents in films prepared by ethyl oxalate $(R E D$ $\left.=0.416, \mathrm{BP}=185.4^{\circ} \mathrm{C}\right)$ and chlorobenzene $(R E D=0.849, \mathrm{BP}$ $=131{ }^{\circ} \mathrm{C}$ ) located below the expected values.

The above method was applied to perovskite precursor solution in DMAC to verify the wide applicability. Figure S14 shows the PXRD patterns of as-cast films formed with different $R E D$ s. Compared to DMF, evaporation of anti-solvent plays a more significant role on the intermediate content. The intermediate contents in as-cast films formed with high boiling point (over $100{ }^{\circ} \mathrm{C}$ ) anti-solvents were low. With a lower $\delta_{\mathrm{DN}}$, DMAC has weaker coordinate interaction with $\mathrm{Pb}$. Meanwhile, anti-solvents have higher affinity (lower RED) to DMAC than DMF. Formation of perovskite is hence easier and more sensitive to the $\varphi_{\text {anti }}$. The volatility of anti-solvent instead of $R E D$ determined the intermediate content in the as-cast film for the sensitivity to $\varphi_{\text {anti }}$. The morphology evolution versus $R E D$ is shown in Figure S15. The films formed with $R E D$ over 0.733 were compact. The anti-solvent evaporation rate also influenced the morphology. Consequently, compact film formed when $R E D=0.430$. The high affinity between DMAC and the antisolvent ensures the formation of azeotrope, where the liquid and vapours have the same $\varphi_{\text {anti }}$. The anti-solvent at $R E D=0.430$ efficiently removes DMAC by both washing out and evaporation. The supersaturation level was hence high yielding a compact film. Application of the method to DMAC revealed the importance of kinetic factors especially for low $\delta_{\mathrm{DN}}$ solvents.

Control of film properties. Solar cells were fabricated with the films prepared under different $R E D$ s. Figure $8 \mathrm{a}$ and $8 \mathrm{~b}$ are the $J-V$ characteristics (Table S3 lists the photovoltaic parameters) and PCE trend, respectively. In this work, the hysteresis-free $J-V$ curves (Figure S16) ensured a valid comparison of photovoltaic performance. The PCE increased 
from $8.15 \%(R E D=0.416)$ to $11.16 \%(R E D=0.726)$ in the low supersaturation region where the average grain sizes were similar. The photovoltaic performance changed as a result of different pinhole and defect densities. The PCE had a sharp increase near $R E D=0.75$ corresponding to the rapid rise of supersaturation level. The PCEs had optimal values of over 12 $\%$ in maximal supersaturation level region $(0.85<R E D<1.00)$. The larger grain sizes and lower defect densities resulted in the superior photovoltaic performance. The perovskite grains formed by the intermediate decomposition has lower defect
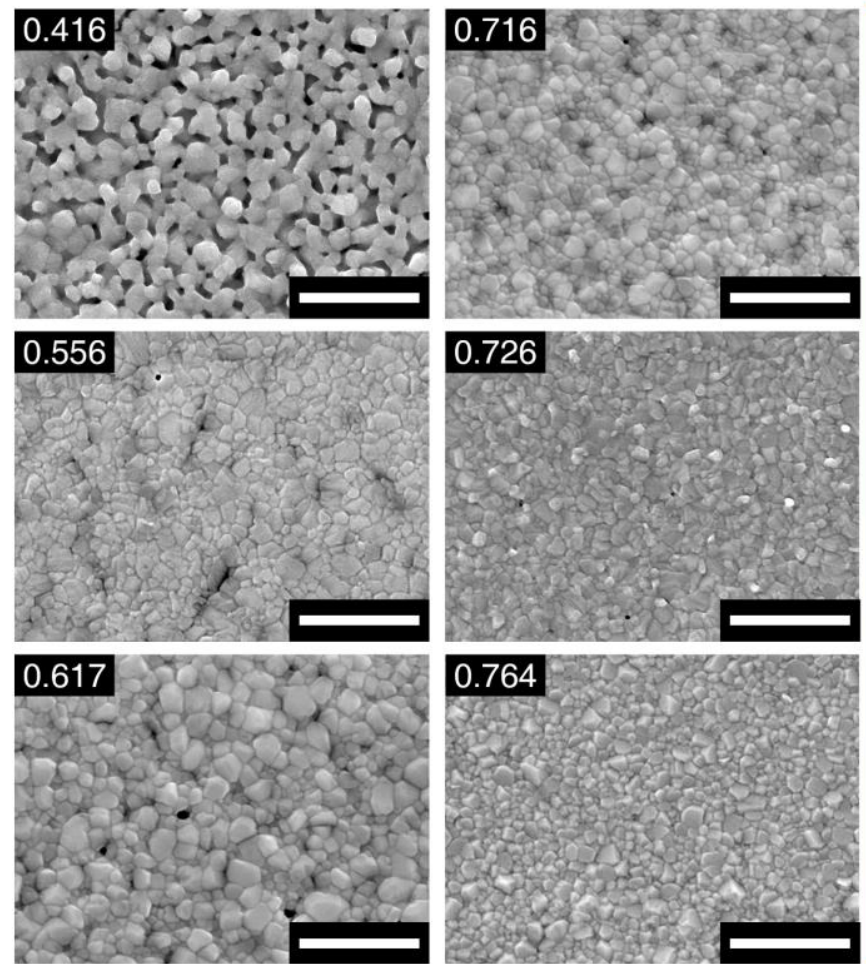

densities. Even though the $\varphi_{\text {anti }}$ was negligible in the wet film when $R E D>1$, the as-formed films had better coverage to the substrates compared to that without anti-solvent quenching. As a result, the photovoltaic performance improved.

The above results allow the expansion of solvent/antisolvent map for perovskite film processing. Table S4 lists 94 liquids with low Lewis basicity, $\delta_{\mathrm{D}}$ and $\delta_{\mathrm{H}}$. They can precipitate perovskite precursor solutions to form films with different mor phologie a nd propertie s.

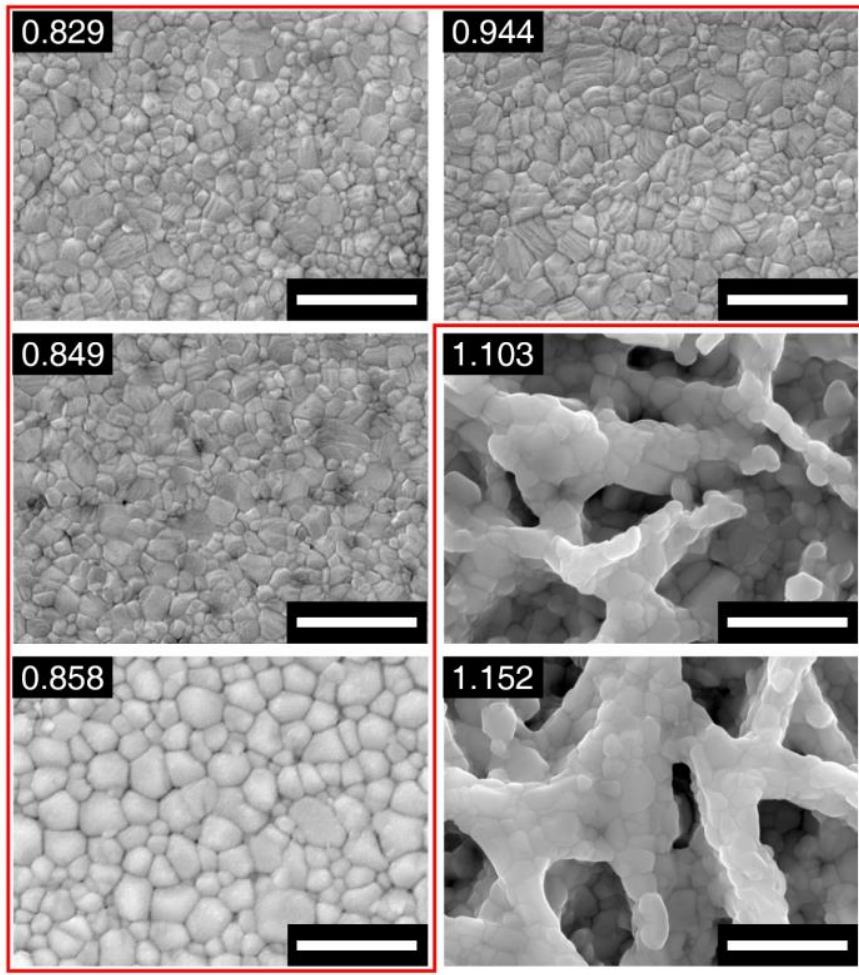

Figure 7. The morphology of calcined perovskite films fabricated with anti-solvents that have different REDs, as shown in the top left-hand corner of each image, with DMF. The scale bars are $1 \mu \mathrm{m}$.

Their REDs with GBL, NMP, DMAC, DMF and DMSO were calculated and plotted in Figure 8c. The solvent/anti-solvent systems with maximal supersaturation levels $(0.85<R E D<$ 1.00) are shaded red.

The anti-solvents were categorised into four types in terms of interaction behaviour with solvated iodoplumbates and $\mathrm{MA}^{+}$ (Figure 8d)). Type I anti-solvents locate in $7.25^{2}<\delta_{\mathrm{P}}^{2}+\delta_{\mathrm{H}}{ }^{2}<$ $12^{2}$ in $\delta_{\mathrm{P}}-\delta_{\mathrm{H}}$ plane. With high $\delta_{\mathrm{P}}$ and $\delta_{\mathrm{H}}$, type I anti-solvents have relatively strong interactions with solvent molecules, solvates and $\mathrm{MA}^{+}$. They have low REDs with solvents and induce low supersaturation levels. Type II anti-solvents $\left(0 \leq \delta_{\mathrm{P}}{ }^{2}+\delta_{\mathrm{H}}{ }^{2}<2\right)$ have very low interaction strength with both the solutes and solvent. Type II anti-solvents are immiscible with the solvents and have limited influence on the film formation process. Type III $\left(2<\delta_{\mathrm{P}}^{2}+\delta_{\mathrm{H}}^{2}<7.25^{2}\right.$ and $\left.\delta_{\mathrm{P}}>\delta_{\mathrm{H}}\right)$ and type IV $\left(2<\delta_{\mathrm{P}}{ }^{2}+\delta_{\mathrm{H}}{ }^{2}\right.$ $<7.25^{2}$ and $\delta_{\mathrm{P}}<\delta_{\mathrm{H}}$ ) anti-solvents have suitable interaction strength with solutes and solvent. Under the high supersaturation levels caused by these anti-solvents, dense films form. Type III anti-solvents have larger $\delta_{\mathrm{P}}$ values and solubilities for the solvates. Conversely, type IV anti-solvents have larger $\delta_{\mathrm{H}}$ values and solubilities for $\mathrm{MA}^{+}$(Figure 8e). The as-cast films prepared with type III anti-solvents would have lower intermediate contents than those prepared with type IV anti-solvents.

DMF and DMSO form iodine deficient intermediate phase $(\mathrm{MA})_{2}(\mathrm{Sol})_{2} \mathrm{~Pb}_{3} \mathrm{I}_{8}$ with perovskite precursors. High intermediate content in the as-cast film yields a $\mathrm{PbI}_{2}$ excess perovskite film. $\mathrm{PbI}_{2}$ in these films passivates the defects at the grain boundaries $^{54-58}$. Perovskite films prepared by type IV antisolvents have larger grain sizes. The solvent molecules released during the calcination and the iodine vacancies facilitate the mass transfer and crystal growth. Hence, type IV anti-solvents are suitable for applications in photovoltaic perovskite film fabrication.

Type I anti-solvent quenched wet films have low intermediate contents for the strong anti-solvent/solvent interactions. The calcined films have low densities of iodine vacancies and high light-emitting performance. Figure $8 \mathrm{f}$ shows the photoluminescence (PL) spectra of perovskite films prepared by different anti-solvents (see Table S6 for HSPs and type identification). As expected, perovskite films prepared by type IV and type I anti-solvents have the lowest and highest PL 
intensities, respectively. The iodine-deficient sample (type IV prepared perovskite film) has a blue-shifted emission peak (Figure S17). The film composition difference is supported by the peak position shift.

Complex systems. Recent solution methods for perovskite film deposition generally use mixed solvents or additives. Perovskite precursors form intermediates with one of the solvent or the additive. Particularly, $(\mathrm{MA})_{2}(\mathrm{DMSO})_{2} \mathrm{~Pb}_{3} \mathrm{I}_{8}$ formation ensures reproducible films with favourable morphology and photovoltaic performance. This work uses the

a

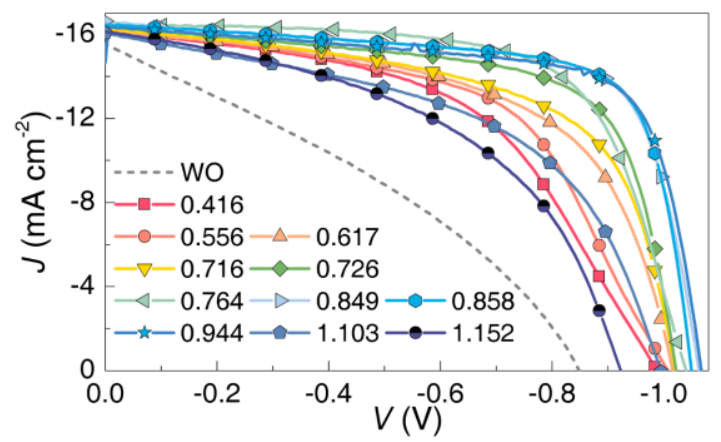

$\mathrm{C}$
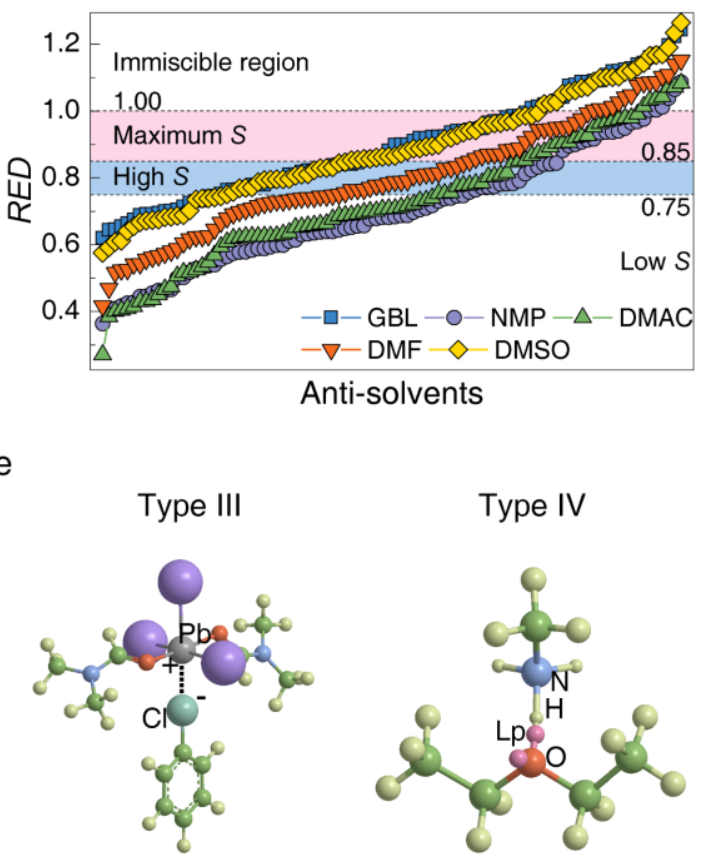

Electrostatic force

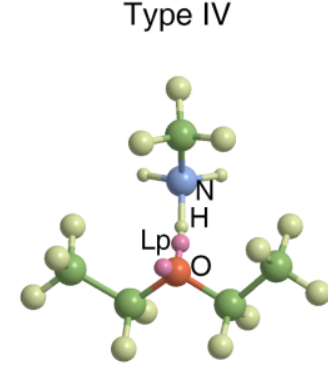

Hydrogen bonding
$R E D$ difference $(\triangle R E D)$ of anti-solvent between different solvents (or solvent/additive) to deal with complex systems. $(\mathrm{MA})_{2}(\mathrm{DMSO})_{2} \mathrm{~Pb}_{3} \mathrm{I}_{8}$ films are typically fabricated by precipitating a DMF/DMSO (4:1 volume ratio) precursor solution with ethyl ether (EE) as the anti-solvent ${ }^{16}$. This work uses the $\triangle R E D$ to maximise the supersaturation level of $(\mathrm{MA})_{2}(\mathrm{DMSO})_{2} \mathrm{~Pb}_{3} \mathrm{I}_{8}$ and improve the film quality. $\triangle R E D$ measures the affinity difference of anti-solvent to the solvent and DMSO. The affinity difference ensures the anti-solvent w $\quad \begin{array}{lllllllllllllll} & \mathrm{a} & \mathrm{s} & \mathrm{h} & \mathrm{e} & \mathrm{s} & \mathrm{t} & \mathrm{h} & \mathrm{e}\end{array}$

b

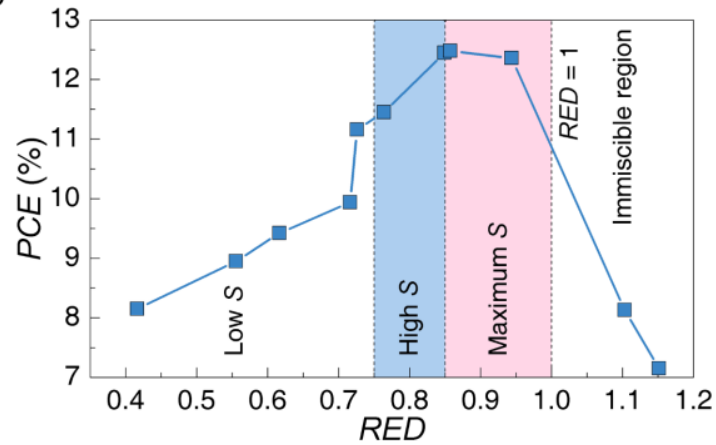

d

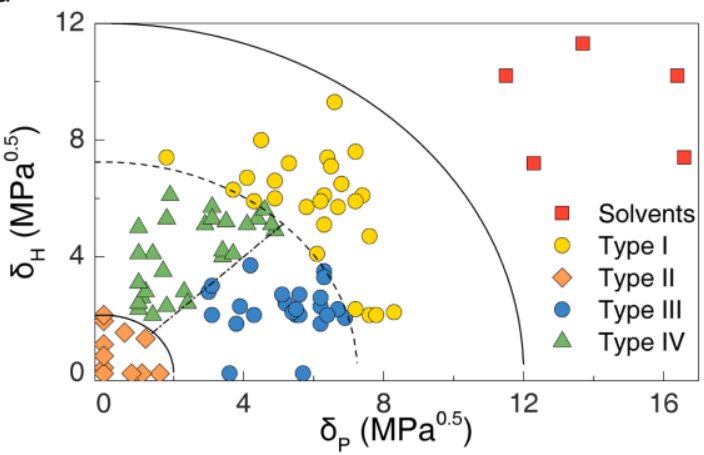

$f$

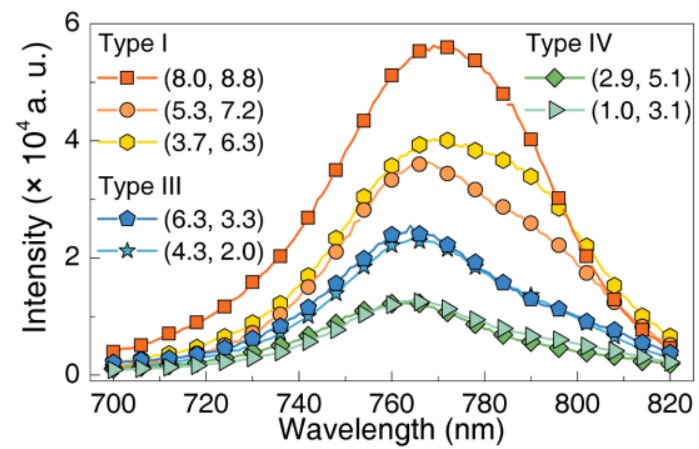

Figure 8. (a) $J-V$ characteristics of perovskite solar cells (PSCs) prepared by anti-solvents with different REDs to DMF; (b) The PCE trend with respect to REDs between anti-solvents and DMF; (c) The REDs between a variety of solvents and anti-solvents (see data in Table S4). The anti-solvents in $0.75<R E D<0.85$ (high supersaturation) and $0.85<R E D<1.00$ (maximal supersaturation) range were highlighted as blue and red; (d) The distribution of anti-solvents and solvents in $\delta_{\mathrm{P}}-\delta_{\mathrm{H}}$ coordinate. The anti-solvents have low interactions with solvates and $\mathrm{MA}^{+}$locate in $\delta \mathrm{P}^{2}+\delta \mathrm{H}^{2}<12^{2}$. According to the interaction behaviour difference, the anti-solvents were divided into four types. Type I: $7.25^{2}<\delta \mathrm{P}^{2}+\delta_{\mathrm{H}}{ }^{2}<12^{2}$, the anti-solvents have relatively high solubilities for solutes and cause low supersaturation levels. Type II: $0<\delta \mathrm{P}^{2}+$ $\delta_{\mathrm{H}^{2}}<2$, the anti-solvents have very low solubilities for solutes. Type II anti-solvents are immiscible with DMF and have limited influence on the film formation process. Type III: $2<\delta_{\mathrm{P}}{ }^{2}+\delta_{\mathrm{H}^{2}}<7.25^{2}$ and $\delta_{\mathrm{P}}>\delta_{\mathrm{H}}$, the anti-solvents cause high supersaturation levels for MA ${ }^{+}$. Type IV: $2<\delta \mathrm{P}^{2}+\delta_{\mathrm{H}^{2}}<7.25^{2}$ and $\delta \mathrm{P}<\delta_{\mathrm{H}}$, the anti-solvents cause high supersaturation levels for solvates; (e) Illustration of the difference in interaction behaviour to solutes between type III and IV anti-solvents. Type III anti-solvents have a stronger interaction with solvates for 
strong electrostatic interactions. Type IV anti-solvents have a stronger interaction with $\mathrm{MA}^{+}$by forming hydrogen bonds. (f) The photoluminescence (PL) spectra of perovskite films prepared by different types of anti-solvents.

solvent out and precipitates DMSO together with perovskite precursors. The anti-solvent should simultaneously have high affinity (low $R E D$ ) to the solvent and low affinities (high $R E D$ ) to DMSO, the iodoplumbates and $\mathrm{MA}^{+}$. The following requirements are identified: (i) the $R E D$ between anti-solvent and solvent should be less than 1 so that anti-solvent can wash the solvent out; (ii) the RED between anti-solvent and DMSO should be larger than 0.9 so that anti-solvent precipitates the DMSO together with perovskite; (iii) the $R E D$ of anti-solvent

a

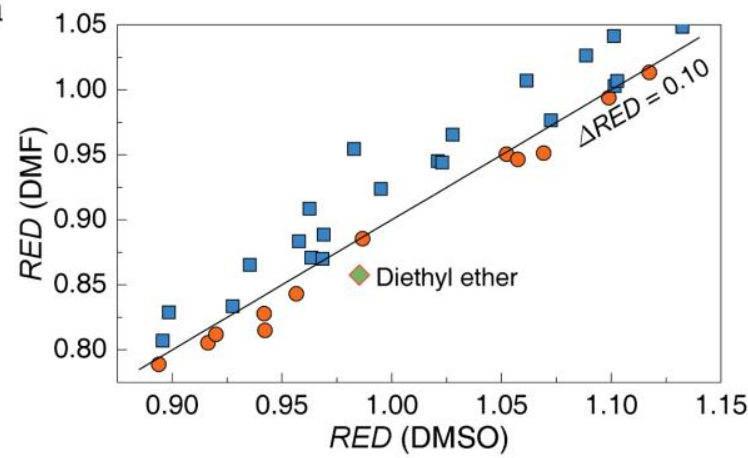

C

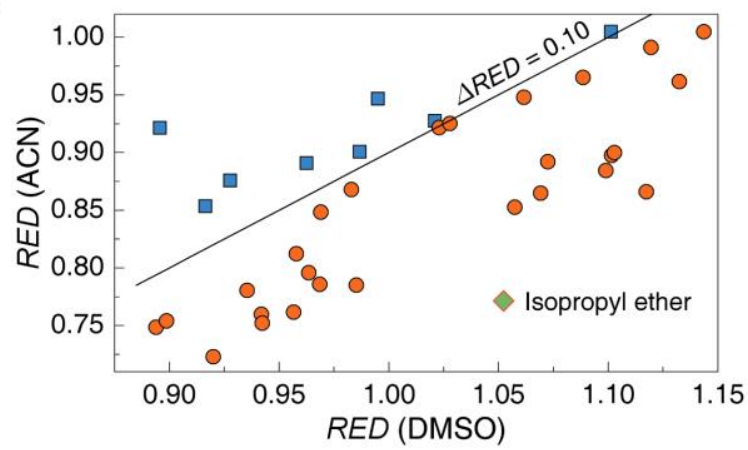

to DMSO should be larger than that of anti-solvent to solvent with a minimal difference of $0.10(\triangle R E D>0.10)$.

Figure 9a are the REDs of a variety of anti-solvents to DMSO (x-axis) and DMF (y-axis). The straight line is the minimal $\triangle R E D$ of 0.10 allowing efficient precipitation of $(\mathrm{MA})_{2}(\mathrm{DMSO})_{2} \mathrm{~Pb}_{3} \mathrm{I}_{8}$ rather than perovskite. Many antisolvents have $\triangle R E D$ smaller than 0.10 when DMF is the solvent. The widely used combination EE-DMF-DMSO has a $\triangle R E D$ of 0.128 , which is close to the maximal $\triangle R E D$ of

b

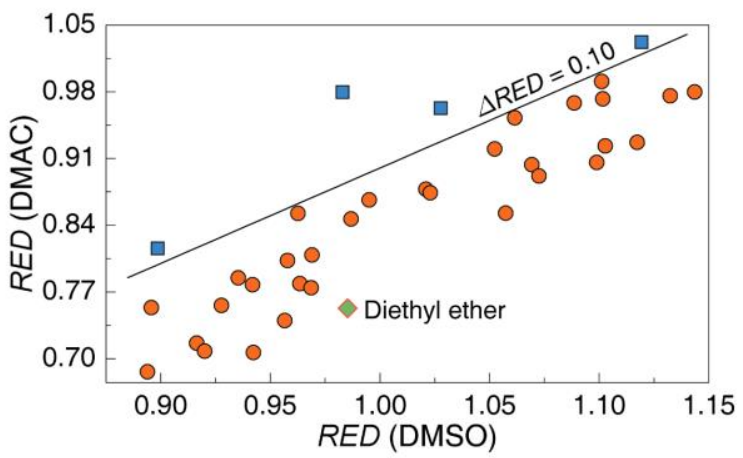

d

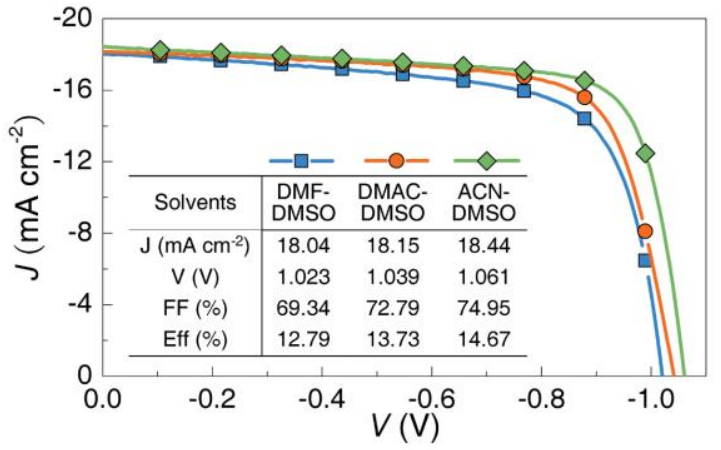

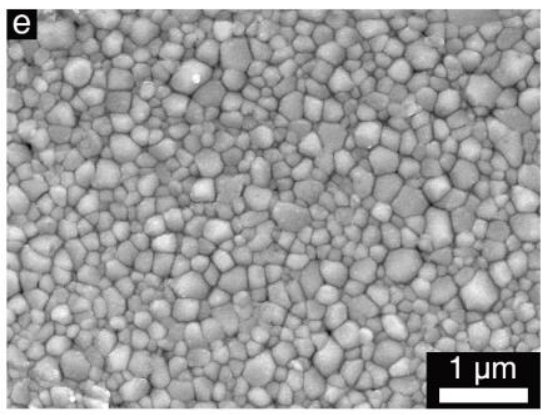
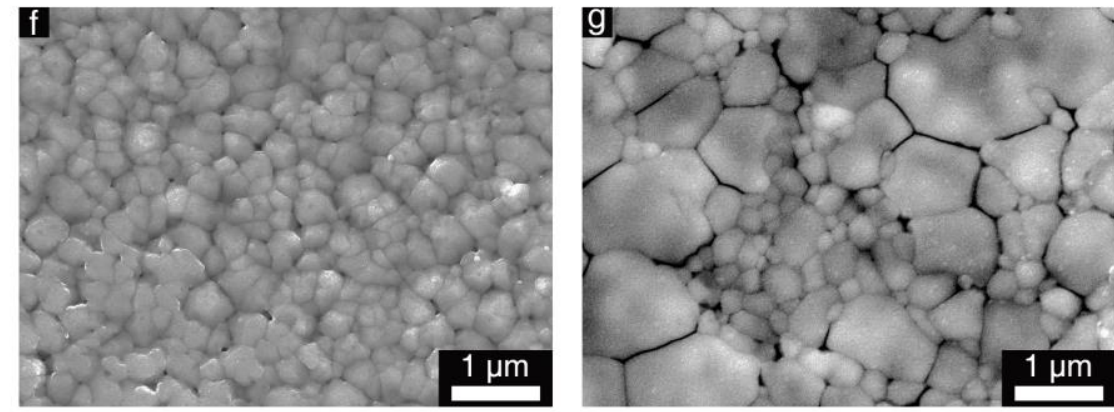

Figure 9. The REDs of anti-solvent/solvent versus REDs of anti-solvent/DMSO for the following solvents: (a) DMF, (b) DMAC and (c) ACN. The green diamonds are the anti-solvents near the maximal $\triangle R E D$ used to fabricate perovskite films; (d) The $J$ - $V$ characteristics and photovoltaic parameters of perovskite solar cells fabricated by precursor solutions with mixed solvents and corresponding anti-solvents; The morphology of perovskite films fabricated by precursor solutions with mixed solvents and corresponding anti-solvents: (e) DMF-DMSO; (f) DMAC-DMSO and (g) ACN-DMSO.

0.133 (allyl methyl ether). To further increase the $\triangle R E D$, solvents with larger affinity to anti-solvents should be used. As shown in Figure $9 \mathrm{~b}$ and 9c, many anti-solvents located far below the minimal $\triangle R E D$ when DMAC and $A C N$ are the solvents, which implies they may be good choices for film preparation. Table S7 lists the anti-solvents/solvent systems with top $3 \triangle R E D s$ for DMSO. Anti-solvents close to the maximal $\triangle R E D$ (green diamonds in Figure 9a-c) were used to prepare perovskite films. The corresponding $J-V$ characteristics are shown in Figure 9d. Compared to DMF, films prepared by DMAC and ACN have significantly larger $V_{O C}$ and $F F$, indicating the decrease in the defect densities. The morphology 
of the films prepared by mixed solvent solutions was also checked (Figure 9e-9g). Compact films formed with all systems. The average grain size increased from $191 \pm 77$ to 428 $\pm 306 \mathrm{~nm}$ (Figure S18). The improvement on grain size and performance proves the increase of supersaturation levels to $(\mathrm{MA})_{2}(\mathrm{DMSO})_{2} \mathrm{~Pb}_{3} \mathrm{I}_{8}$ in high $\triangle R E D$ systems.

The elemental distributions in (mixed ion) perovskites and the associated defects play a significant role on the optoelectronic performance. The elemental distribution is typically determined by (i) film deposition process driven by difference in supersaturation level of halide salts and (ii) annealing process driven by difference in diffusion coefficient of elements (solvent evaporation and temperature inhomogeneity influence diffusion as well). A profound understanding on the interaction-film formation relationship will allow desired elemental distribution catering for a wide range of applications. This work is the start point of developing methods to better control the elemental distribution and associated defects in perovskite film.

\section{CONCLUSIONS}

$\delta_{\mathrm{DN}}$ effectively measures the coordinate bond strength between the donor solvent and a Lewis acid solute. When $\delta_{\mathrm{DN}}>$ $35.53 \mathrm{MPa}^{0.5}$, the intermediates are $(\mathrm{MA})_{2}(\mathrm{sol})_{2} \mathrm{~Pb}_{3} \mathrm{I}_{8}$ and $(\mathrm{MA})_{2}(\mathrm{Sol})_{2} \mathrm{~Pb}_{2} \mathrm{I}_{6}$. Solvents have lower $\delta_{\mathrm{DN}}$ forms polyhedron shaped intermediate $(\mathrm{MA})_{8}(\mathrm{Sol})_{x} \mathrm{~Pb}_{18} \mathrm{I}_{44}$. Suitable solvent for perovskite locates in $\delta_{\mathrm{DN}} \geq 30 \mathrm{MPa}^{0.5}, \delta_{\mathrm{DN}} \geq 0.78 \delta_{\mathrm{P}}-16.86$ $\mathrm{MPa}^{0.5}$ and $\delta_{\mathrm{H}} \leq 12.5 \mathrm{MPa}^{0.5}$ in $\delta_{\mathrm{DN}}-\delta_{\mathrm{P}}-\delta_{\mathrm{H}}$ space. Liquids have $\delta_{\mathrm{H}}$ $>12.5 \mathrm{MPa}^{0.5}$ are breakers which only dissolve MAI. Liquids with $\delta_{\mathrm{H}} \leq 12.5 \mathrm{MPa}^{0.5}$ and $\delta_{\mathrm{P}}<6.5 \mathrm{MPa}^{0.5}$ are ligands $\left(\delta_{\mathrm{DN}} \geq 30\right.$ $\left.\mathrm{MPa}^{0.5}\right)$ or anti-solvents $\left(\delta_{\mathrm{DN}} \leq 30 \mathrm{MPa}^{0.5}\right)$.

The ions, iodoplumbates and colloids in a perovskite precursor solution are in equilibria. Introduction of anti-solvent increases the concentration of colloids and precipitate the solutes. $(\mathrm{MA})_{2}(\mathrm{DMF})_{2} \mathrm{~Pb}_{3} \mathrm{I}_{8},(\mathrm{MA})_{2}(\mathrm{DMF})_{2} \mathrm{~Pb}_{2} \mathrm{I}_{6}$ and $\mathrm{MAPbI}_{3}$ are the main compositions in precipitate when $\varphi_{\text {anti }} \leq 0.952, \varphi_{\text {anti }}$ $=0.980$ and $\varphi_{\text {anti }} \geq 0.999$, respectively. $R E D$ between antisolvent and solvent quantifies the interaction strength. The morphology of perovskite films can be controlled by antisolvents with different REDs. The perovskite films formed under $R E D<0.75$ have pinholes on the surface for the low nuclei density. In the $R E D$ region of $0.85-1.00$, dense perovskite films form under a high nuclei density. Perovskite films prepared by anti-solvent with $R E D>1$ have needle shape grains and low coverage of substrates.

The defects of perovskite film can be controlled by the interaction behaviour difference between anti-solvent and solutes. Type I anti-solvents $\left(7.25^{2}<\delta_{\mathrm{P}}{ }^{2}+\delta_{\mathrm{H}}{ }^{2}<12^{2}\right)$ have strong interaction with the solvent. The films prepared by type I anti-solvents have high light-emitting performance. Type IV anti-solvents $\left(2<\delta_{\mathrm{P}}^{2}+\delta_{\mathrm{H}}^{2}<7.25^{2}\right.$ and $\left.\delta_{\mathrm{P}}<\delta_{\mathrm{H}}\right)$ fabricated perovskite films have high photovoltaic performance.

For complex systems with additives, $\triangle R E D$ effectively predicts the supersaturation level of intermediate formed between perovskite and additive. When $\triangle R E D$ increases from 0.128 to 0.281 , the PCE and average grain size increased by $14.7 \%$ and $124.1 \%$, respectively.
This study demonstrates the utility of quantifying solventsolute interactions for the design of optimal conditions for preparing perovskite films, and the $\delta_{\mathrm{DN}}$ scale may be useful in explaining and improving the preparation of other kinds of inorganic materials.

\section{EXPERIMENTAL}

MAI synthesis. Hydroiodic acid (47 wt \%, Honeywell Fluka) was mixed with methylamine ethanol solution (33 wt \%, Acros Organics) with a molar ratio of $1: 1$ in a round bottom flask in an ice water bath. After reacting for two hours, the product was crystallised by removing the solvent with a rotary evaporator. The solid was dissolved in a minimal volume of ethanol ( $\geq 99.5 \%$, Honeywell) and recrystallised with diethyl ether ( $\geq 99 \%$, anhydrous, Acros Organics). The product was collected by vacuum filtration and washed three times with diethyl ether. The white salt was dried in a vacuum oven at 60 ${ }^{\circ} \mathrm{C}$ for $12 \mathrm{~h}$.

Perovskite film deposition. Perovskite precursor solution $(1.25 \mathrm{M})$ in GBL $(\geq 99 \%$, Sigma-Aldrich), NMP (99.5\%, anhydrous, Sigma-Aldrich), DMAC (99.8\%, anhydrous, Sigma-Aldrich), DMF (99.8 \%, extra dry, Acros Organics) and DMSO ( $\geq 99.5 \%$, anhydrous, Sigma-Aldrich) were prepared by dissolving $\mathrm{PbI}_{2}$ (99\%, Acros Organics) and MAI in these solvents under stirring. Lime soda glass slides were used as the substrates. Precursor solutions in DMF-DMSO and DMACDMSO were prepared by dissolving $1.383 \mathrm{~g} \mathrm{PbI}_{2}$ and $0.477 \mathrm{~g}$ MAI in $2 \mathrm{~mL}$ mixed liquids with volume ratios of $4: 1$. The precursor solution in ACN-DMSO was prepared by mixing 1.5 $\mathrm{M}$ precursor solution in DMSO with equal volume ACN. The glass slides were cleaned with detergent, deionized water and acetone successively in an ultrasonic bath. The substrates were dried with airflow and further cleaned with an ultraviolet-ozone (UV-Ozone) system for two hours. perovskite precursor solutions $(50 \mu \mathrm{L})$ were cast on the cleaned substrates at 5000 $\mathrm{rpm}$. Anti-solvents were injected onto the wet films with certain delay times after rotation start. The delay times for anti-solvents quenching were at 5, 25, 14, 10 and $30 \mathrm{~s}$ for DMF, DMSO, GBL, DMAC and NMP. At these times, the spontaneous nucleation was just about to happen. The precursor solutions in mixed solvents were cast on glass substrates at $5000 \mathrm{rpm}$ for 30 $\mathrm{s}$. The anti-solvents (delay times) used were EE (10 s), EE (12 s) and isopropyl ether (8 s) for DMF-DMSO, DMAC-DMSO and ACN-DMSO, respectively. The as-cast films were calcined on a $100{ }^{\circ} \mathrm{C}$ hotplate for $10 \mathrm{~min}$.

Solar cell fabrication. FTO substrates (NSG, $14 \Omega / \square$ ) were cleaned with detergent, deionized water and acetone successively in an ultrasonic bath. After drying, the substrates were cleaned with a UV-Ozone system. A compact $\mathrm{NiO}_{\mathrm{x}}$ layer was then deposited on the FTO by spin coating a $0.2 \mathrm{M}$ nickel acetate ( $\geq 99.0 \%$, Sigma-Aldrich) and acetylacetone $(\geq 99.5 \%$, Sigma-Aldrich) solution in ethanol. The compact layer was calcined on a $450{ }^{\circ} \mathrm{C}$ hotplate to crystallize the metal oxide. When the hotplate cooled to $200{ }^{\circ} \mathrm{C}$, the substrates were transferred into an alumina boat and further cooled to room temperature. Perovskite films were deposited by spin coating the precursor solutions in DMF, DMF-DMSO, DMAC-DMSO and ACN-DMSO with a spin coater under $5000 \mathrm{rpm}$ (for $30 \mathrm{~s}$ ). The wet films cast by precursor solution in DMF were quenched with different anti-solvents $(750 \mu \mathrm{L})$ after a delay time of $5 \mathrm{~s}$. 
The quenching process lasted for $4 \mathrm{~s}$ on a $25 \mathrm{x} 15 \mathrm{~mm}$ substrate yielding a flow rate of $0.5 \mu \mathrm{L} \mathrm{mm}^{-2} \mathrm{~s}^{-1}$. The anti-solvents (delay times) used were EE (10 s), EE (12 s) and isopropyl ether ( $8 \mathrm{~s})$ for DMF-DMSO, DMAC-DMSO and ACN-DMSO, respectively. The as formed films were annealed on a $100{ }^{\circ} \mathrm{C}$ hotplate for $10 \mathrm{~min}$. After cooling, a $15 \mathrm{mg} \mathrm{mL}^{-1}$ phenyl-C61butyric acid methyl ester (PCBM) solution in $\mathrm{CB}$ was cast on the perovskite films. Finally, $120 \mathrm{~nm} \mathrm{Ag}$ was thermally evaporated as the back contact.

Characterisation. Ultraviolet-visible-near infrared (UVVis-NIR) spectroscopy: the absorbance spectra of perovskite solutions were recorded on a Biochrom Libra S22 spectrometer. The step width and scan speeds were $1 \mathrm{~nm}$ and $750 \mathrm{~nm} \mathrm{~min}{ }^{-1}$, respectively. For the absorbance of perovskite films, the step width and scan speed were the same as the liquid samples.

Powder X-ray diffraction (PXRD): The phase compositions of as cast and calcined films were characterised with powder mode grazing incident XRD (Siemens D500 powder diffractometer). A step width of $0.02^{\circ}$ and a hold time of $0.8 \mathrm{~s}$ on each step were used. $\mathrm{Cu} \mathrm{K} \alpha 1$ irradiation with a wavelength of $1.5406 \AA$ was used as the X-ray source.

Cryogenic transmission electron microscopy (Cryo-TEM): Blank DMF and perovskite precursor solution in DMF (3 uL) were deposited onto a graphene oxide / holey carbon / 300 mesh copper TEM grid. The sample was plunge frozen into liquid ethane with a Gatan CP3 cryoplunge. The sample was transferred under liquid nitrogen to a pre-cooled Gatan 926 cryo sample holder and transferred to a JEOL 2100 plus TEM. Temperature control was via a Gatan Smartset model 900 cold stage controller, the temperature was held at $-176{ }^{\circ} \mathrm{C}$ throughout imaging. Images were recorded at an operating voltage of $200 \mathrm{kV}$, on a Gatan Ultrascan 100XP camera.

Scanning electron microscopy (SEM): The morphology of perovskite films was studied with a field emission scanning electron microscope (JEOL 7100). Carbon (10 nm) was coated to increase the conductivity of the films with a Quorum Q300 ES coater. An acceleration voltage of $15 \mathrm{kV}$ and a working distance of $10 \mathrm{~mm}$ was used.

Photovoltaic performance measurement: The solar cells were tested under a xenon lamp (YAMASHITA DENSO, YSS$150 \mathrm{~A})$, simulating the AM1.5 G sunlight with an energy density of $100 \mathrm{~mW} \mathrm{~cm}^{-2} \mathrm{~s}^{-1}$. The temperature of the solar cells was maintained at $15^{\circ} \mathrm{C}$ with a compact ultra-low temperature chamber (ESPEC MC-711). The J-V characteristics were recorded by an ADCMT 6246 two-channel voltage current source/monitor with a scanning rate of $80 \mathrm{mV} \mathrm{s}^{-1}$.

Photoluminescence spectra: The PL spectra of perovskite films coated on glass substrates were measured with a fluorescence spectrometer (Horiba NanoLog). The wavelength of excitation light was $457 \mathrm{~nm}$. The emission light was filtered by a $550 \mathrm{~nm}$ optical filter before entering the detector.

\section{ASSOCIATED CONTENT}

\section{Supporting Information.}

The Supporting Information is available free of charge on the ACS Publication website at http://pubs.acs.org.

Figures of XRD, SEM, cryo-TEM, UV-Vis absorption spectra, $\mathrm{J}-\mathrm{V}$ hysteresis, grain size distribution data.
Explanations on factors determine perovskite film morphology, calculation of iodoplumbate concentrations, solubility parameters and relative energy difference (RED), solvation of perovskite precursors, kinetic factors in anti-solvent quenching process.

Tables: solubility and properties of pure liquids, REDs between anti-solvents and solvents, photovoltaic performance, $\triangle R E D s$ of anti-solvents to mixed solvents.

\section{AUTHOR INFORMATION}

\section{Corresponding Author}

ming.li@nottingham.ac.uk (Ming Li)

david.amabilino@nottingham.ac.uk (David B. Amabilino)

\section{ORCID}

Lei Lei: 0000-0002-0068-310X

Ming Li: 0000-0002-5456-5846

David M. Grant: 0000-0002-6786-7720

Songwang Yang: 0000-0001-6304-5941

Julie A. Watts: 0000-0002-5292-0445

David B. Amabilino: 0000-0003-1674-8462

\section{Notes}

The authors declare no competing financial interest.

\section{ACKNOWLEDGMENTS}

This work was supported by the Engineering and Physical Sciences Research Council (EPSRC) [under grants EP/L022494/1 and EP/M005178/1] and the University of Nottingham. The authors thank the Nanoscale and Microscale Research Centre (nmRC) for providing access to instrumentation. Especially, we thank the University of Nottingham Beacon of Excellence Propulsion Futures for funding.

\section{REFERENCES}

1. NREL, Best Research-Cell Efficiency Chart. In 2019.

2. Liu, D.; Kelly, T. L., Perovskite Solar Cells with a Planar Heterojunction Structure Prepared Using Room-Temperature Solution Processing Techniques. Nat. Photonics 2014, 8, 133-138.

3. Kumar, M. H.; Yantara, N.; Dharani, S.; Graetzel, M.; Mhaisalkar, S.; Boix, P. P.; Mathews, N., Flexible, Low-Temperature, Solution Processed ZnO-Based Perovskite Solid State Solar Cells. Chem. Commun. 2013, 49, 11089-11091.

4. Wang, J. T.-W.; Ball, J. M.; Barea, E. M.; Abate, A.; AlexanderWebber, J. A.; Huang, J.; Saliba, M.; Mora-Sero, I.; Bisquert, J.; Snaith H. J.; Nicholas, R. J., Low-Temperature Processed Electron Collection Layers of Graphene/TiO 2 Nanocomposites in Thin Film Perovskite Solar Cells. Nano Letters 2013, 14, 724-730.

5. Jingbi You, Z. H., Yang Yang, Qi Chen, Min Cai, Tze-Bin Song, Chun-Chao Chen, Shirong Lu, Yongsheng Liu, Huanping Zhou, and Yang Yang, Low-Temperature Solution-Processed Perovskite Solar Cells with High Efficiency and Flexibility. ACS Nano 2014, 8, 16741680.

6. Huang, A.; Lei, L.; Zhu, J.; Yu, Y.; Liu, Y.; Yang, S.; Bao, S.; Cao, X.; Jin, P., Achieving High Current Density of Perovskite Solar Cells by Modulating the Dominated Facets of Room-Temperature DC Magnetron Sputtered $\mathrm{TiO}_{2}$ Electron Extraction Layer. ACS Appl. Mater. Interfaces 2017, 9, 2016-2022.

7. Huang, A.; Zhu, J.; Zheng, J.; Yu, Y.; Liu, Y.; Yang, S.; Bao, S.; Lei, L.; Jin, P., Room-Temperature Processible $\mathrm{TiO}_{2}$ Electron Selective Layers with Controllable Crystallinity for High Efficiency Perovskite Photovoltaics. Sol. Energy Mater. Sol. Cells 2017, 163, 15-22.

8. Hu, L.; Sun, K.; Wang, M.; Chen, W.; Yang, B.; Fu, J.; Xiong, Z.; Li, X.; Tang, X.; Zang, Z.; Zhang, S.; Sun, L.; Li, M., Inverted Planar 
Perovskite Solar Cells with a High Fill Factor and Negligible Hysteresis by the Dual Effect of NaCl-Doped PEDOT:PSS. ACS Appl. Mater. Interfaces 2017, 9, 43902-43909.

9. Cao, J.; Yu, H.; Zhou, S.; Qin, M.; Lau, T.-K.; Lu, X.; Zhao, N.; Wong, C.-P., Low-Temperature Solution-Processed $\mathrm{NiO}_{\mathrm{x}}$ Films for Air-Stable Perovskite Solar Cells. J. Mater. Chem. A 2017, 5, 1107111077.

10. Manda Xiao, F. H., Wenchao Huang, Yasmina Dkhissi, Ye Zhu, Joanne Etheridge, Angus Gray-Weale, Udo Bach, Yi-Bing Cheng and Leone Spiccia, A Fast Deposition-Crystallization Procedure for Highly Efficient Lead Iodide Perovskite Thin-Film Solar Cells. Angew. Chem. Int. Ed. 2014, 53, 9898-9903.

11. Jeon, N. J.; Noh, J. H.; Kim, Y. C.; Yang, W. S.; Ryu, S.; Seok, S. I., Solvent Engineering for High-Performance Inorganic-Organic Hybrid Perovskite Solar Cells. Nat. Mater. 2014, 13, 897.

12. Xiao, Z.; Dong, Q.; Bi, C.; Shao, Y.; Yuan, Y.; Huang, J., Solvent Annealing of Perovskite-Induced Crystal Growth for PhotovoltaicDevice Efficiency Enhancement. Adv. Mater. 2014, 26, 6503-6509.

13. Jeon, N. J.; Noh, J. H.; Yang, W. S.; Kim, Y. C.; Ryu, S.; Seo, J.; Seok, S. I., Compositional Engineering of Perovskite Materials for High-Performance Solar Cells. Nature 2015, 517, 476-80.

14. Wu, Y.; Yang, X.; Chen, W.; Yue, Y.; Cai, M.; Xie, F.; Bi, E.; Islam, A.; Han, L., Perovskite Solar Cells with $18.21 \%$ Efficiency and Area Over $1 \mathrm{~cm}^{2}$ Fabricated by Heterojunction Engineering. Nat. Energy 2016, 1, 16148.

15. Bi, D.; Tress, W.; Dar, M. I.; Gao, P.; Luo, J.; Renevier, C.; Schenk, K.; Abate, A.; Giordano, F.; Correa Baena, J. P.; Decoppet, J. D.; Zakeeruddin, S. M.; Nazeeruddin, M. K.; Gratzel, M.; Hagfeldt, A., Efficient Luminescent Solar Cells Based on Tailored Mixed-Cation Perovskites. Sci. Adv. 2016, 2, e1501170.

16. Ahn, N.; Son, D.-Y.; Jang, I.-H.; Kang, S. M.; Choi, M.; Park, N.G., Highly Reproducible Perovskite Solar Cells with Average Efficiency of $18.3 \%$ and Best Efficiency of $19.7 \%$ Fabricated via Lewis Base Adduct of Lead(II) Iodide. J. Am. Chem. Soc. 2015, 137, 86968699.

17. Lin, N.; Qiao, J.; Dong, H.; Ma, F.; Wang, L., MorphologyControlled $\mathrm{CH}_{3} \mathrm{NH}_{3} \mathrm{PbI}_{3}$ Films by Hexane-Assisted One-Step Solution Deposition for Hybrid Perovskite Mesoscopic Solar Cells with High Reproductivity. J. Mater. Chem. A 2015, 3, 22839-22845.

18. Yu, Y.; Yang, S.; Lei, L.; Liu, Y., Nucleation Mediated Interfacial Precipitation for Architectural Perovskite Films with Enhanced Photovoltaic Performance. Nanoscale 2017, 9, 2569-2578.

19. Paek, S.; Schouwink, P.; Athanasopoulou, E. N.; Cho, K. T.; Grancini, G.; Lee, Y.; Zhang, Y.; Stellacci, F.; Nazeeruddin, M. K.; Gao, P., From Nano- to Micrometer Scale: The Role of Antisolvent Treatment on High Performance Perovskite Solar Cells. Chem. Mater. 2017, 29, 3490-3498.

20. Chen, C.-C.; Chang, S. H.; Chen, L.-C.; Tsai, C.-L.; Cheng, H.-M.; Huang, W.-C.; Chen, W.-N.; Lu, Y.-C.; Tseng, Z.-L.; Chiu, K. Y.; Chen, S.-H.; Wu, C.-G., Interplay Between Nucleation and Crystal Growth During the Formation of $\mathrm{CH}_{3} \mathrm{NH}_{3} \mathrm{PbI}_{3}$ Thin Films and Their Application in Solar Cells. Sol. Energy Mater. Sol. Cells 2017, 159, 583-589.

21. Chang, S. H.; Huang, W.-C.; Chen, C.-C.; Chen, S.-H.; Wu, C.-G., Effects of Anti-solvent (iodobenzene) Volume on The Formation of $\mathrm{CH}_{3} \mathrm{NH}_{3} \mathrm{PbI}_{3}$ Thin Films and Their Application in Photovoltaic Cells. Appl. Surf. Sci. 2018, 445, 24-29.

22. Wang, Y.; Wu, J.; Zhang, P.; Liu, D.; Zhang, T.; Ji, L.; Gu, X.; David Chen, Z.; Li, S., Stitching Triple Cation Perovskite by a Mixed Anti-Solvent Process for High Performance Perovskite Solar Cells. Nano Energy 2017, 39, 616-625.

23. Zheng, X.; Chen, B.; Wu, C.; Priya, S., Room Temperature Fabrication of $\mathrm{CH}_{3} \mathrm{NH}_{3} \mathrm{PbBr}_{3}$ by Anti-solvent Assisted Crystallization Approach for Perovskite Solar Cells with Fast Response and Small JV Hysteresis. Nano Energy 2015, 17, 269-278.

24. Cohen, B.-E.; Aharon, S.; Dymshits, A.; Etgar, L., Impact of Antisolvent Treatment on Carrier Density in Efficient Hole-Conductor-
Free Perovskite-Based Solar Cells. J. Phys. Chem. C 2016, 120, 142147.

25. Ngo, T. T.; Suarez, I.; Antonicelli, G.; Cortizo-Lacalle, D.; Martinez-Pastor, J. P.; Mateo-Alonso, A.; Mora-Sero, I., Enhancement of the Performance of Perovskite Solar Cells, LEDs, and Optical Amplifiers by Anti-Solvent Additive Deposition. Adv. Mater. 2017, 29, 1604056.

26. Zhang, M.; Wang, Z.; Zhou, B.; Jia, X.; Ma, Q.; Yuan, N.; Zheng, X.; Ding, J.; Zhang, W.-H., Green Anti-Solvent Processed Planar Perovskite Solar Cells with Efficiency Beyond $19 \%$. Sol. RRL 2018, 2, 1700213 .

27. Zhang, J.; Zhai, G.; Gao, W.; Zhang, C.; Shao, Z.; Mei, F.; Zhang, J.; Yang, Y.; Liu, X.; Xu, B., Accelerated Formation and Improved Performance of $\mathrm{CH}_{3} \mathrm{NH}_{3} \mathrm{PbI}_{3}$-Based Perovskite Solar Cells via Solvent Coordination and Anti-solvent Extraction. J. Mater. Chem. A 2017, 5, 4190-4198.

28. Lee, K.-M.; Lin, C.-J.; Liou, B.-Y.; Yu, S.-M.; Hsu, C.-C.; Suryanarayanan, V.; Wu, M.-C., Selection of Anti-Solvent and Optimization of Dropping Volume for the Preparation of Large Area Sub-Module Perovskite Solar Cells. Sol. Energy Mater. Sol. Cells 2017, 172, 368-375.

29. Xiao, M.; Zhao, L.; Geng, M.; Li, Y.; Dong, B.; Xu, Z.; Wan, L.; Li, W.; Wang, S., Selection of an Anti-Solvent for Efficient and Stable Cesium-Containing Triple Cation Planar Perovskite Solar Cells. Nanoscale 2018, 10, 12141-12148.

30. Stevenson J.; Sorenson B.; Subramaniam V. H.; Raiford J.; Khlyabich P. P.; Loo Y. L.; Clancy P., Mayer Bond Order as a Metric of Complexation Effectiveness in Lead Halide Perovskite Solutions. Chem. Mater. 2016, 29, 2435-2444.

31. Rahimnejad, S.; Kovalenko, A.; Forés, S. M.; Aranda, C.; Guerrero, A., Coordination Chemistry Dictates the Structural Defects in Lead Halide Perovskites. ChemPhysChem 2016, 17, 2795-2798.

32. Sharenko, A.; Mackeen, C.; Jewell, L.; Bridges, F.; Toney, M. F., Evolution of Iodoplumbate Complexes in Methylammonium Lead Iodide Perovskite Precursor Solutions. Chem. Mater. 2017, 29, 13151320 .

33. Hamill Jr, J. C.; Schwartz, J.; Loo, Y. L., Influence of Solvent Coordination on Hybrid Organic-Inorganic Perovskite Formation. ACS Energy Lett. 2017, 3, 92-97.

34. Gutmann, V., Empirical Parameters for Donor and Acceptor Properties of Solvents. Electrochim. Acta 1976, 21, 661-670.

35. Hamill, J. C.; Schwartz, J.; Loo, Y. L., Influence of Solvent Coordination on Hybrid Organic-Inorganic Perovskite Formation. ACS Energy Lett. 2018, 3, 92-97.

36. Burger, K., Solvation, Ionic and Complex Formation Reactions in Non-aqueous Solvents: Experiment. Methods for Their Investigation. Elsevier: Amsterdam, 1983.

37. Hansen, C. M., The Universality of the Solubility Parameter. Ind. Eng. Chem. Prod. Res. Dev. 1969, 8, 2-11.

38. Hansen, C. M.,. The Three Dimensional Solubility Parameter-Key to Paint Component Affinities. III. Independent Calculation of the Parameter Components. J. Paint Technol. 1967, 39, 511-520.

39. Gardner, K. L.; Tait, J. G.; Merckx, T.; Qiu, W.; Paetzold, U. W.; Kootstra, L.; Jaysankar, M.; Gehlhaar, R.; Cheyns, D.; Heremans, P.; Poortmans, J., Nonhazardous Solvent Systems for Processing Perovskite Photovoltaics. Adv. Energy Mater. 2016, 6, 1600386.

40. Hansen, C. M., Hansen solubility parameters: a User's Handbook, $2^{\text {nd }}$ ed. CRC press: Boca Raton, 2007.

41. Gutmann, V., Coordination Chemistry in Non-Aqueous Solutions. Springer: Vienna, 1968.

42. Shih, Y. C.; Lan, Y. B.; Li, C. S.; Hsieh, H. C.; Wang, L.; Wu, C. I.; Lin, K. F., Amino-Acid-Induced Preferential Orientation of Perovskite Crystals for Enhancing Interfacial Charge Transfer and Photovoltaic Performance. Small 2017, 13, 1604305.

43. Wang, F.; Geng, W.; Zhou, Y.; Fang, H.-H.; Tong, C.-J.; Loi, M. A.; Liu, L.-M.; Zhao, N., Phenylalkylamine Passivation of Organolead Halide Perovskites Enabling High-Efficiency and Air-Stable Photovoltaic Cells. Adv. Mater. 2016, 28, 9986-9992. 
44. Pan, J.; Quan, L. N.; Zhao, Y.; Peng, W.; Murali, B.; Sarmah, S. P.; Yuan, M.; Sinatra, L.; Alyami, N. M.; Liu, J.; Yassitepe, E.; Yang, Z.; Voznyy, O.; Comin, R.; Hedhili, M. N.; Mohammed, O. F.; Lu, Z. H.; Kim, D. H.; Sargent, E. H.; Bakr, O. M., Highly Efficient PerovskiteQuantum-Dot Light-Emitting Diodes by Surface Engineering. $A d v$. Mater. 2016, 28, 8718-8725.

45. Petrov, A. A.; Sokolova, I. P.; Belich, N. A.; Peters, G. S.; Dorovatovskii, P. V.; Zubavichus, Y. V.; Khrustalev, V. N.; Petrov, A. V.; Grätzel, M.; Goodilin, E. A.; Tarasov, A. B., Crystal Structure of DMF-Intermediate Phases Uncovers the Link Between $\mathrm{CH}_{3} \mathrm{NH}_{3} \mathrm{PbI}_{3}$ Morphology and Precursor Stoichiometry. J. Phys. Chem. C 2017, 121, 20739-20743.

46. Fateev, S. A.; Petrov, A. A.; Khrustalev, V. N.; Dorovatovskii, P. V.; Zubavichus, Y. V.; Goodilin, E. A.; Tarasov, A. B., Solution Processing of Methylammonium Lead Iodide Perovskite from $\gamma$ Butyrolactone: Crystallization Mediated by Solvation Equilibrium. Chem. Mater. 2018, 30, 5237-5244.

47. Stamplecoskie, K. G.; Manser, J. S.; Kamat, P. V., Dual Nature of the Excited State in Organic-Inorganic Lead Halide Perovskites. Energy Environ. Sci. 2015, 8, 208-215.

48. Oldenburg, K.; Vogler, A.; Mikó, I.; Horváth, O., Photoredox Decomposition of tin(II), Lead(II), Antimony(III) and Bismuth(III) Iodide Complexes in Solution. Inorg. Chim. Acta 1996, 248, 107-110. 49. Horváth, O.; Mikó, I., Spectra, Equilibrium and Photoredox chemistry of Tri- and Tetraiodoplumbate(II) Complexes in Acetonitrile. J. Photochem. Photobiol., A 1998, 114, 95-101.

50. Yan, K.; Long, M.; Zhang, T.; Wei, Z.; Chen, H.; Yang, S.; Xu, J., Hybrid Halide Perovskite Solar Cell Precursors: Colloidal Chemistry and Coordination Engineering Behind Device Processing for High Efficiency. J. Am. Chem. Soc. 2015, 137, 4460-4468.
51. Li, B.; Li, M.; Fei, C.; Cao, G.; Tian, J., Colloidal Engineering for Monolayer $\mathrm{CH}_{3} \mathrm{NH}_{3} \mathrm{PbI}_{3}$ Films Toward High Performance Perovskite Solar Cells. J. Mater. Chem.A 2017, 5, 24168-24177.

52. Borrmann, H.; Persson, I.; Sandström, M.; Stålhandske, C. M. V., The Crystal and Liquid Structures of N,N-dimethylthioformamide and N,N-Dimethylformamide Showing a Stronger Hydrogen Bonding

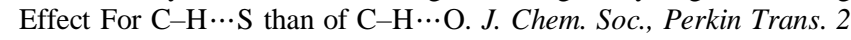
2000, 2, 393-402

53. Stewart, R. J.; Grieco, C.; Larsen, A. V.; Doucette, G. S.; Asbury, J. B., Molecular Origins of Defects in Organohalide Perovskites and Their Influence on Charge Carrier Dynamics. J. Phys. Chem. C 2016, 120, 12392-12402.

54. Wang, L.; McCleese, C.; Kovalsky, A.; Zhao, Y.; Burda, C., Femtosecond Time-Resolved Transient Absorption Spectroscopy of $\mathrm{CH}_{3} \mathrm{NH}_{3} \mathrm{PbI}_{3}$ Perovskite Films: Evidence for Passivation Effect of $\mathrm{PbI}_{2}$. J. Am. Chem. Soc. 2014, 136, 12205-12208.

55. Zhang, T.; Guo, N.; Li, G.; Qian, X.; Zhao, Y., A controllable Fabrication of Grain Boundary $\mathrm{PbI}_{2}$ Nanoplates Passivated Lead Halide Perovskites for High Performance Solar Cells. Nano Energy 2016, 26, 50-56.

56. Kim, Y. C.; Jeon, N. J.; Noh, J. H.; Yang, W. S.; Seo, J.; Yun, J. S.; Ho-Baillie, A.; Huang, S.; Green, M. A.; Seidel, J., Beneficial Effects of $\mathrm{PbI}_{2}$ Incorporated in Organo-Lead Halide Perovskite Solar Cells. Adv. Energy Mater. 2016, 6, 1502104.

57. Chen, Q.; Zhou, H.; Song, T.-B.; Luo, S.; Hong, Z.; Duan, H.-S.; Dou, L.; Liu, Y.; Yang, Y., Controllable Self-Induced Passivation of Hybrid Lead Iodide Perovskites Toward High Performance Solar Cells. Nano letters 2014, 14, 4158-4163.

58. Wang, S.; Dong, W.; Fang, X.; Zhang, Q.; Zhou, S.; Deng, Z.; Tao, R.; Shao, J.; Xia, R.; Song, C., Credible Evidence for the Passivation Effect of Remnant $\mathrm{PbI}_{2}$ in $\mathrm{CH}_{3} \mathrm{NH}_{3} \mathrm{PbI}_{3}$ Films in Improving the Performance of Perovskite Solar Cells. Nanoscale 2016, 8, 6600-6608. 


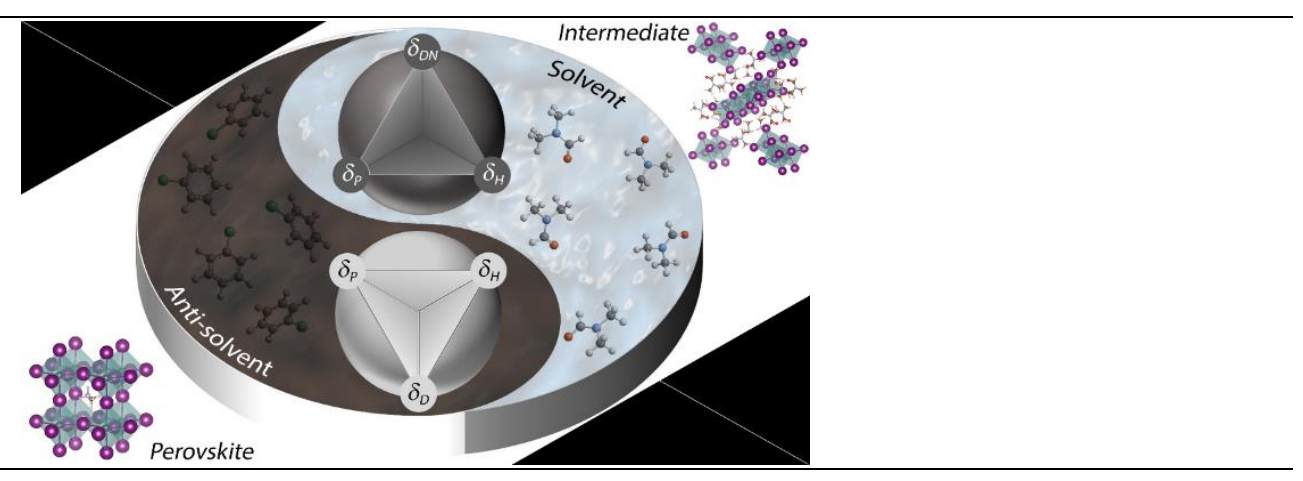

